\title{
Review
}

\section{Review and evaluation of estuarine biotic indices to assess benthic condition}

\author{
Rute Pinto ${ }^{a, *}$, Joana Patrício ${ }^{a}$, Alexandra Baeta ${ }^{a}$, Brian D. Fath ${ }^{b}$, João M. Neto ${ }^{a}$, \\ João Carlos Marques ${ }^{a}$ \\ a Institute of Marine Research (IMAR), c/o Department of Zoology, Faculty of Sciences and Technology, \\ University of Coimbra, 3004-517 Coimbra, Portugal \\ ${ }^{\mathrm{b}}$ Biology Department, Towson University, Towson, MD 21252, USA
}

\section{A R T I C L E I N F O}

\section{Article history:}

Received 1 July 2005

Received in revised form

17 January 2008

Accepted 21 January 2008

Keywords:

Ecosystem integrity

Estuaries

Biotic indices

Benthic communities

Mondego estuary

Ecological indicators

\begin{abstract}
A B S T R A C T
Recently there has been a growing interest and need for sound and robust ecological indices to evaluate ecosystem status and condition, mainly under the scope of the Water Framework Directive implementation. Although the conceptual basis for each index may rely on different assumptions and parameters, they share a common goal: to provide a useful tool that can be used in assessing the system's health and that could be applied in decision making. This paper focuses mainly on benthic community-based, biotic indices. We supply a general overview of several indices premises and assumptions as well as their main advantages and disadvantages. Furthermore, an illustrative example is provided of a straightforward application of benthic index of biotic integrity and benthic condition index. As a reference, their performance is compared to the Portuguese-benthic assessment tool. Limitations of the tested indices are discussed in context of the Mondego estuary (Portugal) case study.
\end{abstract}

(C) 2008 Elsevier Ltd. All rights reserved.

\section{Contents}

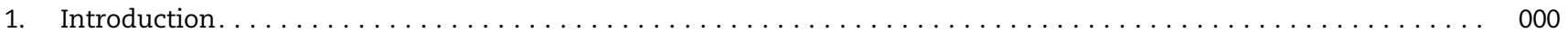

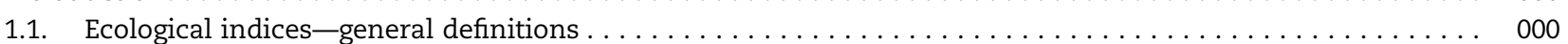

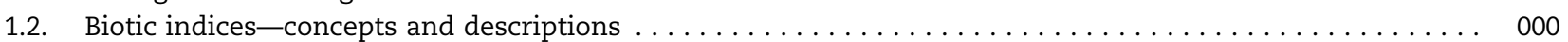

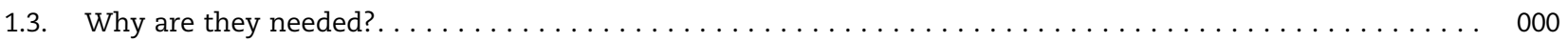

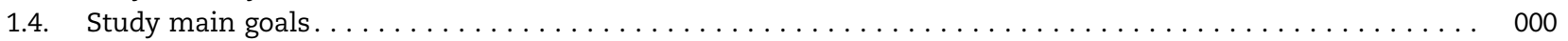

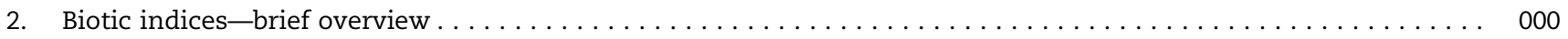

2.1. Acadian province benthic index (APBI; Hale and Heltshe, in press) $\ldots \ldots \ldots \ldots \ldots$

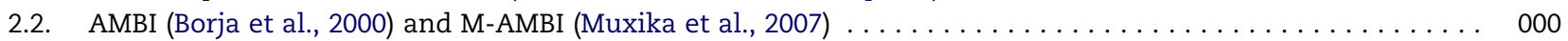

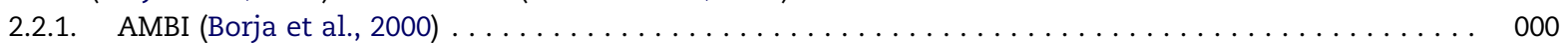

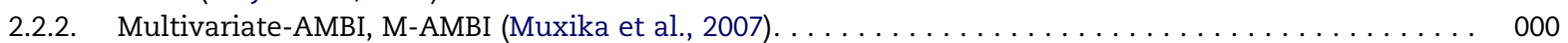

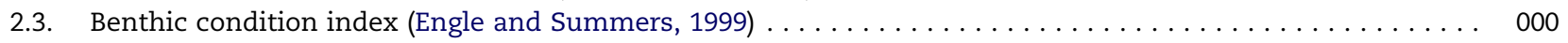

\footnotetext{
* Corresponding author. Fax: +351 239823603.

E-mail address: rutepinto@ci.uc.pt (R. Pinto).

1470-160X/\$ - see front matter (C) 2008 Elsevier Ltd. All rights reserved.

doi:10.1016/j.ecolind.2008.01.005
} 


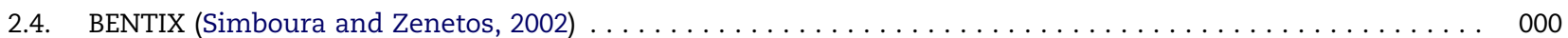

2.5. Benthic habitat quality (BHQ; Nilsson and Rosenberg, 1997) $\ldots \ldots \ldots \ldots \ldots \ldots$

2.6. Benthic opportunistic polychaeta amphipoda (BOPA) index (Dauvin and Ruellet, 2007) . . . . . . . . . 000

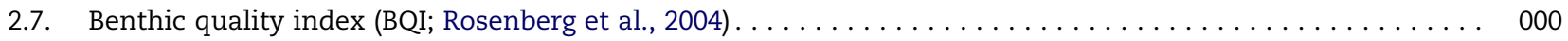

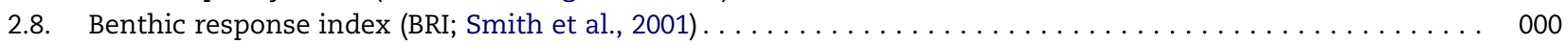

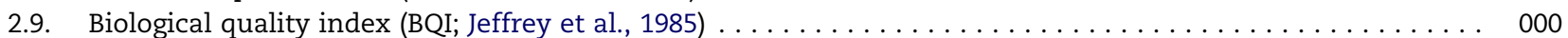

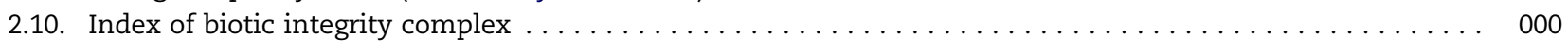

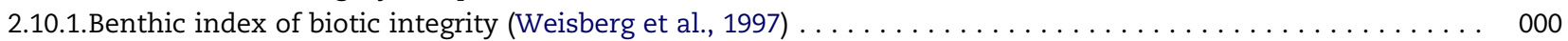

2.10.2. Macroinvertebrate index of biotic integrity (Carr and Gaston, 2002) $\ldots \ldots \ldots \ldots \ldots$

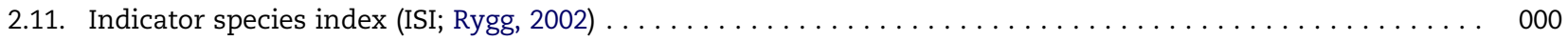

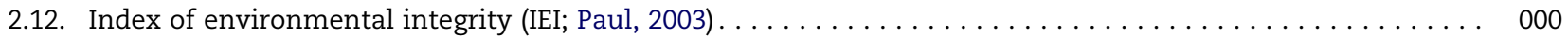

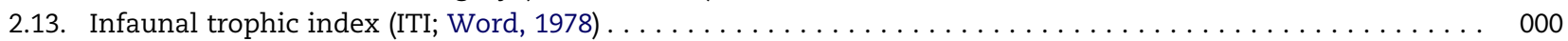

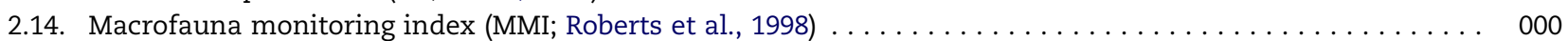

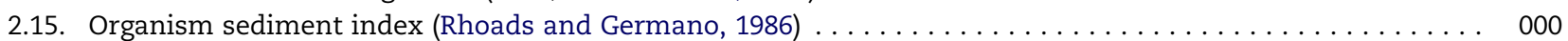

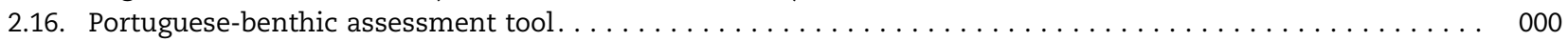

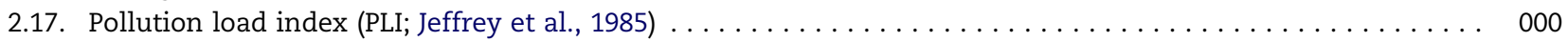

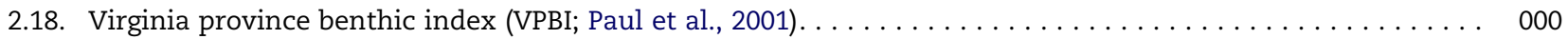

3. Application of three broadly used indices: the Mondego estuary case study. $\ldots \ldots \ldots \ldots$

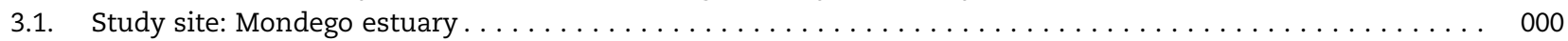

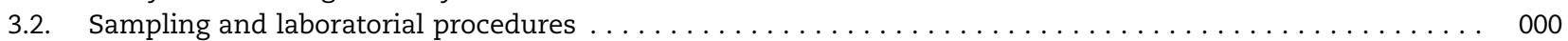

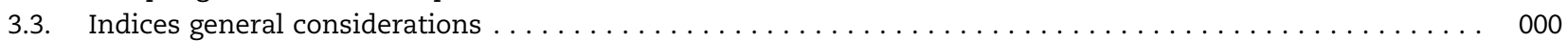

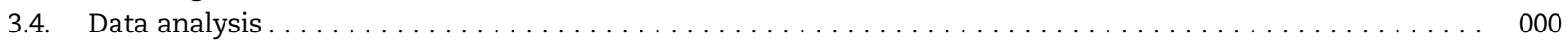

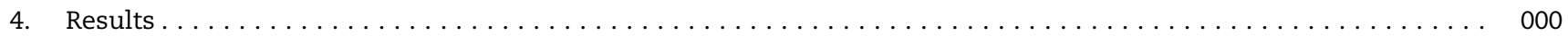

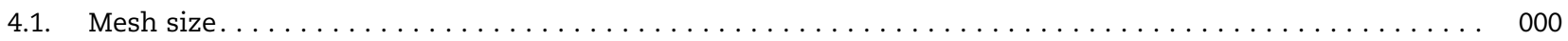

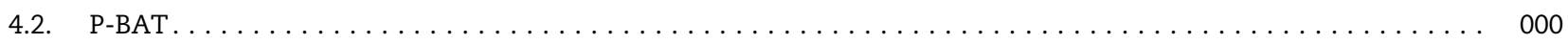

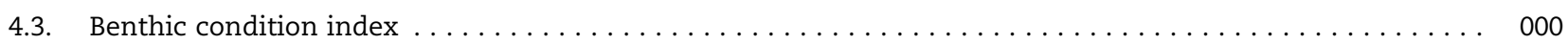

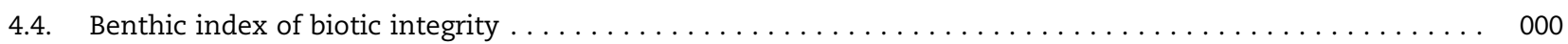

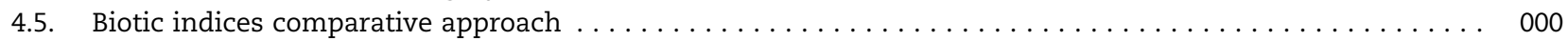

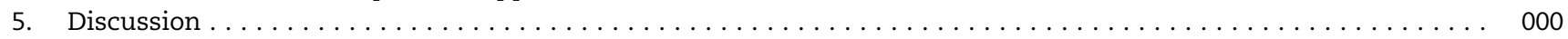

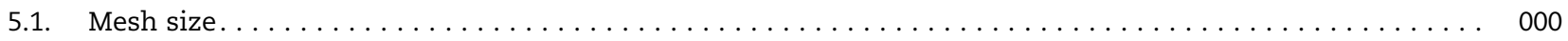

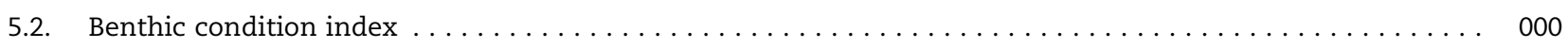

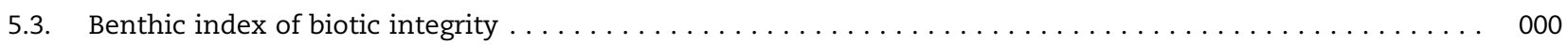

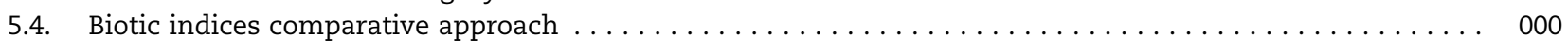

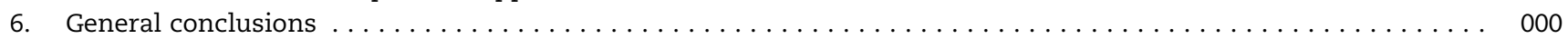

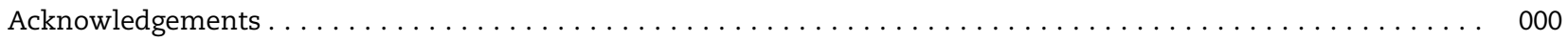

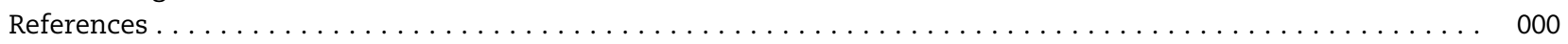

\section{Introduction}

\subsection{Ecological indices-general definitions}

Indicators are designed to provide clear signals about something of interest, to communicate information about the current status, and, when recorded over time, can yield valuable information about changes or trends (NRC, 2000). Furthermore, ecological indices are used as quantitative tools in simplifying, through discrete and rigorous methodologies, the attributes and weights of multiple indicators with the intention of providing broader indication of a resource, or the resource attributes, being assessed (Hyatt, 2001). A clear distinction between indices and indicators must be done. Hereafter, it is considered as an indicator any measure that allows the assessment and evaluation of a system status (descriptive indicators, environmental quality indicators and performance indicators), as well as of any management actions for conservation and preservation that occur in the ecosystem (Dauvin, 2007). By its turn, indices are considered as one possible measure of a system's status. As so, they are often used to evaluate and assess ecological integrity as it relates to a specific qualitative or quantitative feature of the system. Indices are very useful tools in decision-making processes since they describe the aggregate pressures affecting the ecosystem, and can evaluate both the state of the ecosystem and the response of managers. They can be used to track progress towards meeting management objectives and facilitate the communication of complex impacts and management processes to a non-specialist audience. Indicators and indices, therefore, can and should be used to help direct research and to guide policies and environmental programs.

\subsection{Biotic indices-concepts and descriptions}

Selection of effective indicators is a key point in assessing a system's status and condition. Several criteria have been listed and defined as crucial points in order to develop and to apply ecological indices accurately. The difficult task is to derive an indicator or set of indicators that together are able to meet these criteria. In fact, despite the panoply of ecological indicators that can be found in the literature, very often they 
are more or less specific for a given kind of stress, applicable to a particular type of community or site-specific. Additionally, in the process of selecting an ecological indicator or index, data requirement and data availability must be accounted for (Salas et al., 2006). According to the main purposes and objectives of the assessment studies, there are several classifications for ecological indices (e.g., Salas et al., 2006; Engle, 2000). This paper relies heavily upon the applicability and usefulness of biotic indices based on estuarine benthic communities. These indices rely on the fact that biological communities are a product of their environment, and also in that different kind of organisms have different habitat preferences and pollution tolerance. They provide a single number, a value that summarises this complexity (albeit with some loss of information), and can be related statistically to a wide range of physical, chemical and biological measures. The changes in these communities do not only affect the abundance of organisms and the dominance structure, but also their spatial distribution and therefore the spatial heterogeneity of the community. Moreover, these multivariate approaches use the species identity in addition to their abundances. It has been suggested that macrobenthic response may be a more sensitive and reliable indicator of adverse effects than water or sediment quality data since the loss of biodiversity and the dominance of a few tolerant species in polluted areas may simplify the food web to the point of irreversibly changed ecosystem processes (Karr and Chu, 1997; Lerberg et al., 2000). Several characteristics make macrobenthic organisms useful and suitable indicators, such as (1) they live in bottom sediments, where exposure to contaminants and oxygen stress is most frequent (Kennish, 1992; Engle, 2000); (2) most benthos are relatively sedentary and reflect the quality of their immediate environment (Pearson and Rosenberg, 1978; Dauer, 1993; Weisberg et al., 1997); (3) many benthic species have relatively long life spans and their responses integrate water and sediment quality changes over time (Dauer, 1993; Reiss and Kröncke, 2005); (4) they include diverse species with a variety of life features and tolerances to stress, which allow their inclusion into different functional response groups (Pearson and Rosenberg, 1978); (5) some species are, or are prey of, commercially important species (Reiss and Kröncke, 2005); and (6) they affect fluxes of chemicals between sediment and water columns through bioturbation and suspension feeding activities, as well as playing a vital role in nutrient cycling (Reiss and Kröncke, 2005).

\subsection{Why are they needed?}

There is a growing recognition that the current growth of human activity cannot continue without significantly overwhelming ecosystems. The Brundtland Commission (WCED, 1987) defined sustainable development as 'development that meets the needs of the present without compromising the ability of future generations to meet their own needs'. This statement addresses the concern over the extent to which ecosystems can continue to provide functions and services into the future (in terms of ecosystem trophic linkages, biodiversity, biogeochemical cycles, etc.), given the activities of human societies. Therefore, there is an emergent requirement for techniques and protocols that allow the correct status and trends assessment within and between ecosystems. In recent years, there has been a great worldwide appearance of several ecological indices, each one based on specific principles and premises. After the Water Framework Directive implementation (WDF; 2000/60/EC) the use and development of biotic indices flourished, which attempt to cover the benthic requirements within this directive.

The main goal of using biotic indices is the evaluation of the ecosystems' biological integrity. Estuaries are very dynamic environments with unique characteristics, such as salinity, tides or temperature, which can suffer major changes through time and space. Estuaries are considered among the most productive and valuable natural systems in the world (Costanza et al., 1997), acting namely as nurseries and refugees for many fish, bird, molluscs and crustaceans species. To accurately determine this biological integrity, a method is needed that incorporates biotic responses through the evaluation of processes from individuals to ecosystems. Thus, combining several metrics, each of them providing information on a biological attribute, in such way that, when integrated, determines the systems' overall status and condition. This is the main strength of biotic indices, since they allow the integration of the ecosystem's information and parameters (Karr, 1991), providing a broader understanding of the system's processes.

\subsection{Study main goals}

Many site-specific indices have been developed and utilized beyond the capacity for justification (Díaz et al., 2004). An evaluation of the suitability and feasibility of the existing indices is a more urgent task than the development of new ones (Díaz et al., 2004; Borja et al., in press). This paper provides a brief overview of several biotic indices and a summary of the main advantages and constraints of each. Moreover, it considers how some of those indices can be used to assess the state and trends of estuarine ecosystems worldwide. We use data from the Mondego estuary (Portugal) to evaluate the indices' adequacy and accurateness in assessing ecological condition. Furthermore, the Portuguesebenthic assessment tool (P-BAT), benthic index of biotic integrity (B-IBI), and benthic condition index (BCI) are used to test the independency of the study site location and sampling protocol particularly mesh size.

\section{Biotic indices-brief overview}

\subsection{Acadian province benthic index (APBI; Hale and Heltshe, in press)}

This index resulted from the need to develop a multivariate tool for the Gulf of Maine. The intent was to use this index as an ecological indicator of benthic condition along the coast and for year-to-year comparisons. To achieve this point, environmental standards - called benthic environmental quality (BEQ) scores - that would be used as reference conditions during the index development and performance were established. The APBI is based on each station BEQ classifications that the best candidate metrics were selected 
and tested and gave rise to the APBI development. The authors also considered the predictive value of an indicator, based on the function of its sensitivity, specificity, and the prevalence of the condition it is supposed to indicate. The positive predictive value (PPV) is the probability of a positive response (low BEQ), given that the indicator is positive (low APBI). The negative predictive value (NPV) is the probability of negative response, given that the indicator is negative.

Being the $\operatorname{Logit}(p)$ the function from multivariate logistic regression, the model that best fit the obtained data for that particular region and conditions, among a broad range of different combinations of benthic metrics, was the one given by

$$
\begin{aligned}
\operatorname{Logit}(p)= & 6.13-0.76 \mathrm{H}^{\prime}-0.84 \mathrm{Mn} \_\mathrm{ES}(50) .05 \\
& + \text { 0.05PctCapitellidae }
\end{aligned}
$$

where $H^{\prime}$ is the Shannon-Wiener diversity index, with higher scores representing higher mean diversity; Mn_ES(50).05 is the station mean of Rosenberg et al. (2004) species tolerance value (higher scores meaning more pollution sensitivity); and PctCapitellidae is the percent abundance of Capitellidae polychaetes, once more, higher scores meaning more capitellids, which do well in organically enriched sediments. Based on this the index probability can be computed as:

$p=\frac{\mathrm{e}^{(\operatorname{Logit}(p))}}{1+\mathrm{e}^{(\operatorname{Logit}(p))}}$

where $p$ is the probability that BEQ is low. A higher $H^{\prime}$ and Mn_ES(50).05 increases this probability an higher PctCapitellidae lowers it. Through the subtraction of this from 1 gives an index where low values indicate low BEQ. The APBI was then scaled to the range $0-10$ by multiplying by 10 :

$\mathrm{APBI}=10 \times(1-p)$

This index was developed to encompass a wide range of habitats and conditions; nevertheless, according to the authors the choice of a smaller subset of data (e.g. mud, or a smaller geographic area) will lower the variability and result in a more accurate indicator. The APBI has been applied in the scope of the NCA Northeast report (USEPA, 2006) and National Coastal Condition Report III (USEPA, 2007); nevertheless, it should undergo a series of validations and calibrations processes in order to be accepted as a universal index (Hale and Heltshe, in press). The authors also point out that the efficiency of this index is unknown for low salinity areas, and since it was designed to be applied in soft-bottom communities it has a higher discriminating impact in mud than in sand areas. Furthermore, this index has been developed using summer data, as so the seasonality effects should be assessed as well. Nonetheless, this index also pretended to examine if the Signal Detection Theory can help to evaluate the ability of the APBI to detect a degraded benthic environment, demonstrating that it can be used as a guide in the decisions that environmental managers have to take about thresholds and where to assign resources (Hale and Heltshe, in press). In addition, the PPV-NPV techniques can be used to foresee how well an index developed for one geographic area might work in another region with different incidence of degraded conditions.

\subsection{AMBI (Borja et al., 2000) and M-AMBI (Muxika et al., 2007)}

\subsubsection{AMBI (Borja et al., 2000)}

The marine biotic index relies on the distribution of individual abundances of the soft-bottom communities into five ecological groups (Grall and Glémarec, 1997):

Group I: Species very sensitive to organic enrichment and present under unpolluted conditions.

Group II: Species indifferent to enrichment, always present in low densities with non-significant variations with time. Group III: Species tolerant to excess organic matter enrichment. These species may occur under normal conditions; however, their populations are stimulated by organic enrichment.

Group IV: Second-order opportunistic species, adapted to slight to pronounced unbalanced conditions.

Group V: First-order opportunistic species, adapted to pronounced unbalanced situations.

The species were distributed in those groups according to their sensitivity to an increasing stress gradient (enrichment of organic matter) (Hily, 1984; Glémarec, 1986). This index is based on the percentages of abundance of each ecological group of one site (biotic coefficient (BC)), which is given by

Biotic coefficient $=\left\{\begin{array}{r}\left(0 \times \% \mathrm{G}_{\mathrm{I}}\right)+\left(1.5 \times \% \mathrm{G}_{\mathrm{II}}\right)+\left(3 \times \% \mathrm{G}_{\mathrm{III}}\right) \\ +\left(4.5 \times \% \mathrm{G}_{\mathrm{IV}}\right)+\left(6 \times \% \mathrm{G}_{\mathrm{V}}\right)\end{array}\right\}$

The marine biotic index, also referred to as $\mathrm{BC}$, varies continuously from 0 (unpolluted) to 7 (extremely polluted) (Table 1).

It is possible to detect the impact of anthropogenic pressures in the environment with this index because it can be used to measure the evolution of the ecological status of a particular region. Fore example, Muxika et al. (2005) have tested it in different geographical sites such as the Basque Country coast-line, Spain, for where it was originally designed (Borja et al., 2000), the Mondego estuary, Portugal (Salas et al., 2004), three locations on the Brazilian coast and two on the Uruguayan coast (Muniz et al., 2005), and has been tested among different geographical sites (Muxika et al., 2005), allowing correct evaluations of the ecosystem's conditions. As so, this index can constitute a sound tool for management due to its capacity to assess ecosystem health.

One drawback of AMBI is that mistakes can occur during the grouping of the species into different groups according to their response to pollution situations. Once it draws on the response of organisms to organic inputs in the ecosystem it does not detect the effects caused by other types of pollution, as for instance toxic pollution (Marín-Guirao et al., 2005). Moreover, this index presents some limitations when applied to semi-enclosed systems (Blanchet et al., 2007). 
Table 1 - Biotic indices values and classifications

Biotic index

Index value

Classification

\begin{tabular}{|c|c|c|c|}
\hline AMBI & $\begin{array}{l}0.0 \leq B C \geq 0.2 \\
0.2 \leq B C \geq 1.2 \\
1.2 \leq B C \geq 3.3 \\
3.3 \leq B C \geq 4.3 \\
4.3 \leq B C \geq 5.0 \\
5.0 \leq B C \geq 5.5 \\
5.5 \leq B C \geq 6.0 \\
\text { Azoic }\end{array}$ & $\begin{array}{l}\text { Normal } \\
\text { Normal } \\
\text { Slightly polluted } \\
\text { Disturbed } \\
\text { Disturbed } \\
\text { Heavily disturbed } \\
\text { Heavily disturbed } \\
\text { Extremely disturbed }\end{array}$ & \\
\hline M-AMBI & $\begin{array}{l}>0.82 \\
0.62-0.82 \\
0.41-0.61 \\
0.20-0.40 \\
<02.0\end{array}$ & & $\begin{array}{l}\text { High } \\
\text { Good } \\
\text { Fair } \\
\text { Poor } \\
\text { Bad }\end{array}$ \\
\hline Benthic index & $\begin{array}{l}>0 \\
<0\end{array}$ & $\begin{array}{l}\text { Good } \\
\text { Poor }\end{array}$ & \\
\hline BENTIX & $\begin{array}{l}4.5 \leq \text { BENTIX } \geq 6.0 \\
3.5 \leq \text { BENTIX } \geq 4.5 \\
2.5 \leq \text { BENTIX } \geq 3.5 \\
2.0 \leq \text { BENTIX } \geq 2.5 \\
0\end{array}$ & $\begin{array}{l}\text { Normal/pristine } \\
\text { Slightly polluted, transitional } \\
\text { Moderately polluted } \\
\text { Heavily polluted } \\
\text { Azoic }\end{array}$ & $\begin{array}{l}\text { High } \\
\text { Good } \\
\text { Moderate } \\
\text { Poor } \\
\text { Bad }\end{array}$ \\
\hline Benthic quality index & $\begin{array}{l}1 \text { to }<4 \\
4 \text { to }<8 \\
8 \text { to }<12 \\
12 \text { to }<16 \\
16 \text { to }<20\end{array}$ & $\cos 2 \cos 2 \cos$ & $\begin{array}{l}\text { Bad } \\
\text { Poor } \\
\text { Moderate } \\
\text { Good } \\
\text { High }\end{array}$ \\
\hline BCI & $\begin{array}{l}<3 \\
3-5 \\
>5\end{array}$ & $\begin{array}{l}\text { Degraded conditions } \\
\text { Transition conditions } \\
\text { Non-degraded sites }\end{array}$ & \\
\hline BHQ & $\begin{array}{l}15 \text { to }>11 \\
11 \text { to }>7 \\
7 \text { to }>4 \\
4 \text { to }>2 \\
0 \text { to } 2\end{array}$ & $\begin{array}{l}3(>10) \\
2(5-10) \\
1 \\
0\end{array}$ & $\begin{array}{l}\text { High } \\
\text { Good } \\
\text { Fair } \\
\text { Poor } \\
\text { Bad }\end{array}$ \\
\hline B-IBI & $\begin{array}{l}\leq 0.2 \\
2.1-2.6 \\
2.7-2.9 \\
\geq 3\end{array}$ & $\begin{array}{l}\text { Severely degraded } \\
\text { Degraded } \\
\text { Marginal } \\
\text { Meets restoration goals }\end{array}$ & \\
\hline BOPA & $\begin{array}{l}0.00000 \leq \text { BOPA } \leq 0.06298 \\
0.04576<\text { BOPA } \leq 0.19723 \\
0.13966<\text { BOPA } \leq 0.28400 \\
0.19382<\text { BOPA } \leq 0.30103 \\
0.26761<\text { BOPA } \leq 0.30103\end{array}$ & $\begin{array}{l}\text { Unpolluted sites } \\
\text { Slightly polluted sites } \\
\text { Moderately polluted sites } \\
\text { Heavily polluted sites } \\
\text { Extremely polluted sites }\end{array}$ & $\begin{array}{l}\text { High } \\
\text { Good } \\
\text { Moderate } \\
\text { Poor } \\
\text { Bad }\end{array}$ \\
\hline BRI & $\begin{array}{l}0-33 \\
34-43 \\
44-72 \\
>72\end{array}$ & $\begin{array}{l}\text { Marginal deviation } \\
\text { Loss of biodiversity } \\
\text { Loss of community function } \\
\text { Defaunation }\end{array}$ & \\
\hline IEI & $\begin{array}{l}5(>40 \% \text { area of indicator }) \\
3(20-40 \% \text { area of indicator }) \\
1 \text { ( }<20 \% \text { area of indicator })\end{array}$ & $\begin{array}{l}\text { Good } \\
\text { Fair } \\
\text { Poor }\end{array}$ & \\
\hline ISI & $\begin{array}{l}>8.75 \\
7.5-8.75 \\
6.0-7.5 \\
4.0-6.0 \\
0-4.0\end{array}$ & & $\begin{array}{l}\text { High } \\
\text { Good } \\
\text { Fair } \\
\text { Poor } \\
\text { Bad }\end{array}$ \\
\hline ITI & $\begin{array}{l}0-30 \\
30-60 \\
60-80 \\
80-100\end{array}$ & $\begin{array}{l}\text { Degraded conditions } \\
\text { Intermediate conditions } \\
\text { Normal conditions } \\
\text { Reference conditions }\end{array}$ & \\
\hline
\end{tabular}

Please cite this article in press as: Pinto, R. et al., Review and evaluation of estuarine biotic indices to assess benthic condition, Ecol. Indicat. (2008), doi:10.1016/j.ecolind.2008.01.005 


\begin{tabular}{|c|c|c|c|}
\hline Biotic index & Index value & Classification & ECoQs \\
\hline MMI & $\begin{array}{l}<2 \\
2-6 \\
>6\end{array}$ & $\begin{array}{l}\text { Severe impact } \\
\text { Patchy impact } \\
\text { No impact }\end{array}$ & \\
\hline OSI & $\begin{array}{l}<0 \\
0 \text { to }<7 \\
7-11\end{array}$ & $\begin{array}{l}\text { Degraded benthic habitat } \\
\text { Disturbed benthic habitat } \\
\text { Undisturbed benthic habitat }\end{array}$ & \\
\hline P-BAT & $\begin{array}{l}>0.77 \\
0.53-0.77 \\
0.41-0.53 \\
0.2-0.41 \\
<0.20\end{array}$ & & $\begin{array}{l}\text { High } \\
\text { Good } \\
\text { Moderate } \\
\text { Poor } \\
\text { Bad }\end{array}$ \\
\hline
\end{tabular}

\subsubsection{Multivariate-AMBI, M-AMBI (Muxika et al., 2007)}

This refined and integrative formula was designed in response to the WFD requirements to include other metrics describing the benthic community integrity (e.g. abundance, biomass or diversity measures) and parameters that are considered to define better the water bodies' ecological quality status (EcoQS). Moreover, it is intended to support the European Marine Strategy Directive (Borja, 2006), in assessing the ecological status of continental shelf and oceanic water bodies (Muxika et al., 2007). The M-AMBI is a combination of the proportion of 'disturbance-sensitive taxa', through the computation of the AMBI index, species richness (it uses the total number of species, $S$ ), and diversity through the use of the Shannon-Wiener index, which overcame the need to use more than one index to evaluate the overall state and quality of an area (Zettler et al., 2007). These parameters are integrated through the use of discriminant analysis (DA) and factorial analysis (FA) techniques. This method compares monitoring results with reference conditions by salinity stretch, for estuarine systems, in order to derive an ecological quality ratio (EQR). These final values express the relationship between the observed values and reference condition values. At 'high' status, the reference condition may be regarded as an optimum where the EQR approaches the value of one. At 'bad' status, the EQR approaches the zero value. The M-AMBI analysis relies on the Euclidean distance ratio between each area and the reference spots, together with the distance between high status and bad status reference condition (Muxika et al., 2007). The stations are located between the reference conditions and have $\mathrm{M}$-AMBI values ranging from 0 to 1 . The boundaries that allow the distinction of the five ecological states are given in Table 1.

The M-AMBI has been the outcome from the intercalibration process among states members for the WFD common methodologies; nevertheless, it has been applied to other systems outside Europe, like in Chesapeake Bay, USA, where it revealed to be a consistent measure, providing high agreement percentages with local indices (Borja et al., in press). A main advantage attributed to this index, as well as of AMBI, is that both are easily computed, and the software can be freely downloaded at http://www.azti.es. Moreover, the M-AMBI seems to provide a more accurate system classification in low salinity habitats, than the AMBI alone (Muxika et al., 2007; Borja et al., in press).

\subsection{Benthic condition index (Engle and Summers, 1999)}

The BCI was designed to evaluate the environmental condition of degraded systems comparatively to reference situations (non-degraded conditions) based on the response of benthic organisms to environmental stressors. This index, which results from the refinement of a previous attempt (Engle et al., 1994), reflects the benthic community responses to perturbations in the natural system (Engle, 2000). The benthic index includes: (1) Shannon-Wiener diversity index adjusted to salinity; (2) mean abundance for Tubificidae; (3) percentages of abundance of the class bivalvia; (4) percentages of abundance of the family Capitellidae; and (5) percentages of abundance of the order amphipoda.

To calculate this index, one first needs to calculate the expected Shannon-Wiener diversity index, according to the bottom salinity:

$$
\begin{aligned}
\mathrm{H}_{\text {expected }}^{\prime}= & 2.618426-(0.044795 \times \text { salinity })+(0.007278 \\
& \left.\times \text { salinity }^{2}\right)+\left(-0.000119 \times \text { salinity }^{3}\right)
\end{aligned}
$$

The final Shannon-Wiener's score is given by dividing the observed by the expected diversity values. After the calculation of the abundance and proportions of the organisms involved, it is necessary to log transform the abundances and arcsine transform the proportions. Based on this, the discriminant score is calculated as:

Discriminant score $=(1.5710$

$$
\begin{aligned}
& \times \text { proportion of expected diversity }) \\
& +(-1.0335 \\
& \times \text { mean abundance of Tubificidae }) \\
& +(-0.5607 \times \text { percent Capitellidae }) \\
& +(-0.4470 \times \text { percent Bivalvia }) \\
& +(0.5023 \times \text { percent Amphipoda })
\end{aligned}
$$


To turn the index in a practicable and easily understood measure by policy-makers, the final benthic index score is given by

Benthic index $=$ discriminant score $-\left(\frac{-3.21}{7.50}\right) \times 10$

where -3.21 is the minimum of the discriminant score, and 7.50 is the range of the discriminant score.

When a community is affected by contaminants, the benthic organisms diminish in abundance and number of species, while there is an increase in the abundance of opportunistic or pollution tolerant species. After the discriminant score transformation, the benthic index can range between 0 and 10, being the general scores classifications presented in Table 1. According to the authors, this index classifies benthic communities' condition within and among estuaries.

\subsection{BENTIX (Simboura and Zenetos, 2002)}

The BENTIX index was based on the AMBI index (Borja et al., 2000) and relies on the reduction of macrozoobenthic data from soft-bottom substrata in three wider ecological groups. To accomplish this goal, a list of indicators species was elaborated, where each species received a score, from 1 to 3, that represented their ecological group. In the light of the above the groups can be described as:

Group 1 (GI): includes the species that are sensitive or indifferent to disturbances (k-strategies species);

Group 2 (GII): includes the species that are tolerant and may increase their densities in case of disturbances, as well as the second-order opportunistic species ( $r$-strategies species);

Group 3 (GIII): includes the first-order opportunistic species.

The formula that expresses this index is given by

$\mathrm{BENTIX}=\left\{\frac{6 \times \% \mathrm{GI}+2 \times(\% \mathrm{GII}+\% \mathrm{GIII})}{100}\right\}$

This index can range from 2 (poor conditions) to 6 (high EcoQS or reference sites) (Table 1). Overall, the BENTIX index considers two major classes of organisms: the sensitive and the tolerant groups. This classification has the advantage of reducing the calculation effort while diminishing the probability of the inclusion of species in inadequate groups (Simboura and Zenetos, 2002). Moreover, when using this index, it does not require for amphipoda identification expertise, since it encloses all those organisms (with exception to individuals from the Jassa genus) in the same category of sensitivity to organic matter increasing (Dauvin and Ruellet, 2007). The BENTIX index was developed in the scope of the WFD for the Mediterranean Sea. It has been successfully applied to cases of organic pollution (Simboura and Zenetos, 2002; Simboura et al., 2005), oil spills (Zenetos et al., 2004) and in dumping of particulate metalliferous waste (Simboura et al.,
2007). This index is considered an ecologically relevant biotic index since it does not under or overestimates the role of any of the groups (Simboura et al., 2005). Nevertheless, according to some authors, the BENTIX index relies solely on the classification of organisms for organic pollution, being unable to accurately classify sites with toxic contaminations (MarínGuirao et al., 2005). It is also emphasized the small lists of species, especially crustaceans, included in the attribution of the scores. Another point is that this index presents some limitations when applied to estuaries and lagoons (Simboura and Zenetos, 2002; Blanchet et al., 2007).

\subsection{Benthic habitat quality (BHQ; Nilsson and Rosenberg, 1997)}

The benthic habitat quality (BHQ) was designed to evaluate the environmental condition of the soft-bottom habitat quality of Havstensfjord (Baltic Sea) through analysis of sediment profile and surface images (SPIs). The BHQ index relies on the relation between the classical distribution of benthic infaunal communities in relation to organic enrichment, based on the Pearson and Rosenberg model (1978). This tool integrates the structures on the sediment surface, structures in the sediment, and the redox potential discontinuity (RPD) images. Therefore, the parameterization of sediment and animal features may be a useful combination to describe and assess habitat quality (Rhoads and Germano, 1986). This index attempts to show the usefulness of sediment profile imaging in demonstrating benthic habitat changes connected with physical disturbance, specifically with low oxygen concentrations (Nilsson and Rosenberg, 2000). The calculation of the BHQ index from the sediment profile images can be computed by

$\mathrm{BHQ}=\sum \mathrm{A}+\sum \mathrm{B}+\mathrm{C}$

where $A$ is the measure of surface structures, $B$ the measure of the subsurface structures, and $C$ the mean sediment depth of the apparent RPD. The parameters used in this index were all measured from the images and the scoring could be seen as an objective assessment of the successional stages. Deep subsurface activity, such as feeding voids and many burrows, which often is associated with a thick RPD, have a high scoring and contribute to a high BHQ index. It can range between 0 and 15 (Table 1), where high scores are associated with mature benthic faunal successional stages and low scores with pioneering stages or azoic bottoms. According to Rosenberg et al. (2004), the BHQ index could also be a useful tool for the WFD implementation in assessing the BHQ. Therefore, instead of the earlier separation of the BHQ index into four successional stages, Rosenberg et al. (2004) underpin the division into five classes in accordance to the WFD requirements (Table 1). According to the index authors, this scoring method can be valid for many boreal and temperate areas, as in these areas the benthic infauna is similarly structured and has a similar distribution and activity within the sediment (Pearson and Rosenberg, 1978; Rhoads and Germano, 1986). Despite sharing some principles, one main difference that distinguishes these two indices is that in the organism sediment index (OSI) (Rhoads and Germano, 1986; see Section 2.15) the successional 
stages are determined by examining the images by eye whereas in the BHQ index the different structures in the images are scored and their summary relates to a particular community stage (Nilsson and Rosenberg, 2000).

One advantage enumerated by the BHQ authors is the fact that a benthic quality assessment based on numerical scoring, as the one used in the BHQ index, allows statistical comparisons between strata and communities. Furthermore, this method can also roughly forecast oxygen regimes over integrative time scales, becoming a useful tool for environmental managers interested in benthic assessment and in rough but quantitative approximation of near bottom dissolved oxygen regimes (Cicchetti et al., 2006). Moreover, the use of SPI methods is a rapid and inexpensive way of tracking and assessing the BHQ, being very useful to characterize the successional stages of the organic enrichment gradient (Nilsson and Rosenberg, 2000; Wildish et al., 2003). Nevertheless, according to Wildish et al. (2003) there are some benthic habitats where this method cannot be applied, as for example in areas where soft-bottoms are absent and where coarse sediments or rock predominate; or even in areas where water depth exceeds reasonable SCUBA diving depths (approximately $30 \mathrm{~m}$ ).

\subsection{Benthic opportunistic polychaeta amphipoda (BOPA) index (Dauvin and Ruellet, 2007)}

The benthic opportunistic polychaeta amphipoda (BOPA) index results from the refinement of the polychaeta/amphipoda ratio (Gómez-Gesteira and Dauvin, 2000), in order to be applicable under the WFD perspective. Accordingly, this index can be used to assign estuarine and coastal communities into five EcoQs categories (Table 1). This index, in accordance with the taxonomic sufficiency principle, aims to exploit this ratio to determine the ecological quality, using relative frequencies $([0 ; 1])$ rather than abundances $([0 ;+\infty])$ in order to define the limits of the index. This way, it can be written as:

$\mathrm{BOPA}=\log \left\{\frac{f_{\mathrm{P}}}{f_{\mathrm{A}}+1}+1\right\}$

where $f_{\mathrm{P}}$ is the opportunistic polychaeta frequency (ratio of the total number of opportunistic polychaeta individuals to the total number of individuals in the sample); $f_{\mathrm{A}}$ is the amphipoda frequency (ratio of the total number of amphipoda individuals, excluding the opportunistic Jassa amphipod, to the total number of individuals in the sample), and $f_{P}+f_{A} \leq 1$. Its value can range between 0 (when $f_{P}=0$ ) and Log 2 (around 0.30103, when $f_{A}=0$ ). The BOPA index will get a null value only when there are no opportunistic polychaetes, indicating an area with a very low amount of organic matter. As so, when the index presents low values it is considered that the area has a good environmental quality, with few opportunistic species; and it increases as increasing organic matter degrades the environment conditions.

One of the main advantages of this index is its independence of sampling protocols, and specifically of mesh sieves sizes, since it uses frequency data and the proportion of each category of organisms. The need for taxonomic knowledge is reduced, which allows a generalised use and ease of implementation. Moreover, the use of frequencies makes it independent of the surface unit chosen to express abundances and it is sensitive to increasing organic matter in sediment as well as to oil pollution. Nevertheless, it takes into account only three categories of organisms - opportunistic polychaetes, amphipods (except Jassa) and other species - but only the first two have a direct effect on the index calculation. Another point is that it does not consider the oligochaeta influence, which may include also opportunistic species.

\subsection{Benthic quality index (BQI; Rosenberg et al., 2004)}

The benthic quality index (BQI) was designed to assess environmental quality according to the WFD. Tolerance scores, abundance, and species diversity factors are used in its determination. The main objective of this index is to attribute tolerance scores to the benthic fauna in order to determine their sensitivity to disturbance. The index is expressed as:

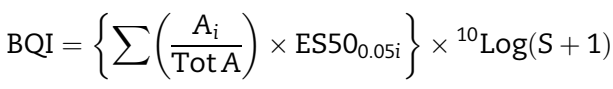

where $A_{i} /$ Tot $A$ is the mean relative abundance of this species, and $\mathrm{ES} \mathrm{O}_{0.05 i}$ the tolerance value of each species, $i$, found at the station. This metric corresponds to $5 \%$ of the total abundance of this species within the studied area. Further, the sum is multiplied by base 10 logarithm for the mean number of species (S) at the station, as high species diversity is related to high environmental quality. The goal of using the values calculated from the 5\% lowest abundance of a particular species $\left(\mathrm{ES} \mathrm{O}_{\mathrm{O} .05}\right)$ is that this value is assumed to be representative for the greatest tolerance level for that species along an increasing gradient of disturbance, i.e. if the stress slightly increases that species will disappear. This method is similar to that proposed by Gray and Pearson (1982) and presents the advantage of reducing the weight of outliers during the index calculation. This parameter can be computed as:

$\mathrm{ES} 50=1-\sum_{i=1}^{S} \frac{\left(N-N_{i}\right) !(N-50) !}{\left(N-N_{i}-50\right) ! N !}$

where $N$ is the total abundance of individuals, $N_{i}$ is the abundance of the $i$-th species, and $S$ is the number of species at the station.

Results from this analysis can range between 0 and 20 (reference value) according to the classification made by the WFD for the coastal environmental status (Table 1). Two methodological constrains of this index can be highlighted: the sample area is not the same among sampling protocols, and individuals' distribution among species may not be random, particularly when some species appear as strong dominants. Thus, Rosenberg et al. (2004) recommend the use of many stations and replicates for the quality assessment of an area. Moreover, according to Zettler et al. (2007) this index presents strong correlations with environmental variables, such as salinity, decreasing the scores with decreasing salinities. Furthermore, this index requires regional datasets (the $\mathrm{ES} 5 \mathrm{O}_{0.05}$ calculation is based on the specific framework of species present at the study-area), and the delimitation of 
local reference values, depending on the areas under study such that different maximum values can be achieved (Rosenberg et al., 2004; Reiss and Kröncke, 2005; Labrune et al., 2006; Zettler et al., 2007).

\subsection{Benthic response index (BRI; Smith et al., 2001)}

The benthic response index (BRI) was developed for the Southern California coastal shelf and is a marine analogue of the Hilsenhoff index used in freshwater benthic assessments (Hilsenhoff, 1987). This index is calculated using a two-step method in which ordination analysis is employed to establish a pollution gradient. Afterwards the pollution tolerance of each species is determined based upon its abundance along the gradient (Smith et al., 1998). The index main goal is to establish the abundance-weighted average pollution tolerance of the species in a sample, which is considered a very useful screening tool (Bergen et al., 2000). The basis of this index is that each species has a tolerance for pollution and if that tolerance is known for a large set of species, then it is possible to infer the degree of degradation from species composition and its tolerances (Gibson et al., 2000). The index can be given as:

$$
I_{s}=\frac{\sum_{i=1}^{n} p_{i} \sqrt[3]{a_{s i}}}{\sum_{i=1}^{n} \sqrt[3]{a_{s i}^{f}}}
$$

where $I_{S}$ is the index value for the sample $s, n$ is the number of species in the sample $s, p_{i}$ is the tolerance value for species $i$ (position on the gradient of pollution), and $a_{\mathrm{si}}$ is the abundance of species $i$ in sample s. The exponent $f$ is for transforming the abundance weights. So, if $f=1$, the raw abundance values are used; if $f=0.5$, the square root of the abundances are used; and if $f=0, I_{s}$ is the arithmetic value of the $p_{i}$ values greater than zero, once that all $a_{s i}^{f}=1$ (Smith et al., 2001). The average position for each species $\left(p_{i}\right)$ on the pollution gradient defined in the ordination space is measured as:

$p_{i}=\frac{\sum_{j=1}^{\mathrm{ti}} g_{\mathrm{ij}}}{\mathrm{ti}}$

where ti is the number of samples to be used in the sum, with only the highest ti species abundance values included in the sum. The $g_{i j}$ is the position of the species $i$ on the ordination gradient for sample $j$. The $p_{i}$ values obtained in Eq. (14) are used as pollution tolerance scores in Eq. (13) to compute the index values.

This index provides a quantitative scale ranging from 0 to 100 , where low scores are indicative of healthier benthic communities (i.e. community composition most similar to that occurring at unimpacted regional reference sites). The BRI scoring defines four levels of response beyond reference condition (Table 1). Although it can be useful to quantify disturbances, it is not able to distinguish between natural and anthropogenic disturbance, such as the natural impacts that river flows may have on benthic communities (Bergen et al., 2000). Nevertheless, this index presents the advantage of not underestimating biological effects, as well as presenting low seasonal variability (Smith et al., 2001).

\subsection{Biological quality index (BQI; Jeffrey et al., 1985)}

The biological quality index (BQI) is based on biosedimentary communities (Wilson, 2003), such as Scrobicularia plana, Macoma balthica, and Hediste diversicolor. This index detects pollution in estuaries, although there are some problems in the detection of the pollution status between that of stable communities and abiotic environments. A number of approaches have been tried in the marine environment. These include the use of the log-normal distribution (Gray, 1979) and the use of diversity indices such as the ShannonWeiner or indicator species (Eagle and Rees, 1973). The index is given by

$\mathrm{BQI}=\operatorname{antilog}_{10}(\mathrm{C}-\mathrm{A})$

where $C$ is the proportional biological area and $A$ is the proportional abiotic area. $A+B+C=1.0$, where $B$ is the opportunistic.

The estuary BQI is obtained by the addition of each zone BQI multiplied by the proportional area of their respective zones. The index can range from 0.1 (completely abiotic) to a maximum of 10 (completely unpolluted). This classification was based on the communities' division into abiotic (without macrobiota), opportunistic, or stable (biological communities usually present in that kind of substrate; Wilson, 2003). Although, it gives a rapid and effective overview, it does not offer a complex discrimination of a system (Wilson, 2003).

\subsection{Index of biotic integrity complex}

Many variations of IBI (Karr, 1991) have been developed for freshwater systems. This index design has been adapted and applied to several other systems, such as terrestrial environments, lacustrine systems, estuaries or coral reefs, using a wide range of metrics that better characterize the system under study, such as macroinvertebrates (e.g. Weisberg et al., 1997), fishes (e.g. Deegan et al., 1997), or coral reefs (e.g. Jameson et al., 2001). Indices like the Chesapeake Bay B-IBI (Weisberg et al., 1997) or the macroinvertebrate index of biotic integrity (mIBI) (Carr and Gaston, 2002) are examples of ecological measures that try to integrate several features and characteristics of a particular system in order to evaluate its condition, using for it the study of the benthic communities present in the system. These two indices are designed to evaluate the ecological health of an estuary.

2.10.1. Benthic index of biotic integrity (Weisberg et al., 1997) The Chesapeake Bay B-IBI (Weisberg et al., 1997) integrates several benthic attributes, related to healthy benthic community structure, in order to calculate the global condition of a region. It gives the actual status of the benthic community as a function of its deviation from the reference condition. Therefore it can provide trends within the system once calibrated to reference conditions. The indicators used to calculate the benthic index are: (1) Shannon-Wiener species diversity index; (2) total species abundance; (3) total species biomass; (3) percent abundance of pollution indicative taxa; (4) percent abundance of pollution sensitive taxa; (5) percent 
biomass of pollution indicative taxa; (6) percent biomass of pollution sensitive taxa; (7) percent abundance of carnivore and omnivore species; (8) percent abundance of deep-deposit feeders; (9) tolerance score and (10) Tanipodinae to Chironomidae percent abundance ratio.

To calculate the index metrics several steps have to be implemented (Llansó, 2002). The epifaunal species have to be eliminated from the species lists and from the calculation, as well as other individuals that are not representative of the subtidal communities (e.g. Nematoda or fish species). To calculate the diversity measure $\left(H^{\prime}\right)$, higher taxonomic groups have to be retained as well (e.g. polychaeta or amphipoda). The sensitive/indicative pollution species can be classified according to the AMBI species classification, considering the I and II ecological groups as sensitive to pollution and the ecological groups IV and V as pollution indicative species. When field and experimental data are not available for feeding strategies metrics (\% of carnivore-omnivore species and \% subsurface deposit feeders), a literature review can be made in order to classify all the catched species.

Although the B-IBI index integrates eleven metrics, not all of them are used here to calculate the overall ecosystem score and condition. Llansó et al. (2002a) defined seven major estuarine stretches for the Chesapeake Bay, according to the Venice transitional water organization scheme for salinity and sediment types. Depending on the estuarine stretch under analysis, different metrics are used to estimate the local condition and status (Table 2). Moreover, the tolerance score and the percentage of Tanipodinae to Chironomidae metrics were considered by the index authors as facultative, as long as no score was attributed to them and that, for the oligohaline zone, the lack of the two metrics was considered in the index average calculation (removed from the denominator factor). This index classification gives scores for the different indicators in relation to the reference conditions. When the two situations are identical, a score of 5 is given and when they are very different a score of 1 is attributed. The final index score is determined by the average of the individual scores (Llansó et al., 2002b). Table 1 gives the final classification of the benthic community condition.

Other indices have been developed having the B-IBI as a role model, nevertheless adapted for other geographical systems (e.g. Van Dolah et al., 1999).

\subsubsection{Macroinvertebrate index of biotic integrity (Carr and} Gaston, 2002)

The mIBI is a multimetric index that was designed to evaluate the benthic condition of an ecosystem, and was developed specifically for application to the Calcasieu estuary (USA). The index is composed of four metrics: (1) abundance of pollution sensitive organisms (ranked in a decreasing order); (2) abundance of pollution tolerant organisms (ranked in an increasing order); (3) total abundance and (4) species diversity.

The indicator species considered are based on the work of Rakocinski et al. (1997) that divided the species into categories of pollution tolerant or pollution sensitive. After summing each metric for each site, the scores are ranked and normalized. The metric data are normalized with the attribution of scores to accurately weight of the metrics in the index. This was achieved by using the rank-normalized data in order to provide a better precision for data analysis and to avoid the distribution of the data. In the end, the index classification falls within a scale of 0 (worst conditions) to 1 (best conditions).

\subsection{Indicator species index (ISI; Rygg, 2002)}

The indicator species index (ISI), that is based on the improved version of the Hurlbert index (1971), focuses on the assumption that each species reacts differently to pollution impacts, and consequently to the degradation of the ecosystem conditions. Knowing the species sensitivity to pollution factors, their presence or absence can be used to calculate the ISI in each sample (it does not enter with taxa abundance). To calculate this index it is necessary to determine the sensitive values for each species as well as the pollution impact factor (ES100min5). The ES100 is the expected number of species among 100 individuals. The average of the five lowest ES100 was defined as the sensitivity value of that taxon, denoted ES100min5. The ISI is then defined as the average of the sensitivity values of the taxa occurring in the sample. This index allows an accurate description of environmental quality of the systems and has been applied mostly in the Norway coasts.

One main disadvantage of the ISI is that it may not be transposed to other geographical regions without restrictions, since the taxonomic list can be significantly different and the calculation of the sensitivity factors may require different

Table 2 - Metrics used to calculate the final B-IBI scores according to estuarine zones

$\begin{array}{ccccc}\text { Euhaline } & \text { Polyhaline } & \text { Polyhaline } & \text { Mesohaline } & \text { Oligohaline } \\ \text { estuarine } & \text { suddy } & \text { sand } & & \\ & & \end{array}$

Shannon-Wiener diversity measure

Total species abundance

Total species biomass

$\%$ Abundance pollution indicative sp

$\%$ Biomass pollution indicative sp.

$\%$ Abundance pollution sensitive sp.

$\%$ Biomass pollution sensitive sp.

$\%$ Carnivore-omnivore sp.

$\%$ SsDF sp.

\% Tanipodinae to Chironomidae

Tolerance score 
approaches. Table 1 provides the ranges of classification in accordance to the WFD requirements.

\subsection{Index of environmental integrity (IEI; Paul, 2003)}

The index of environmental integrity (IEI) was developed to assess the overall condition of a region and was first used in the Mid-Atlantic region. This index is based on the evaluation of signals derived from natural or anthropogenic sources given by the natural systems. These signals are then used to identify the condition of the system and the causes that provoked it. The IEI final value is obtained through the integration of the weighted average of individual subindex values, which is given as:

$\mathrm{IEI}=\frac{\sum^{n} w_{\mathrm{i}} \mathrm{I}_{\mathrm{i}}}{\sum^{n} w_{\mathrm{i}}}$

where $w_{i}$ is the weight for the subindex $i, I_{i}$ is the value for the subindex $i$; and $n$ the number of subindex values.

To establish the final classification, values were assigned to each parameter for each area according to the percent area for the indicator (Table 1). When applying this index it must be considered that it was based on a restricted number of indicators.

\subsection{Infaunal trophic index (ITI; Word, 1978)}

The infaunal trophic index (ITI) was initially designed to identify degraded environmental conditions caused by organic pollution along the California coasts. This index, a numeric representation of the relative abundance of the dominant infaunal organisms, is based on the distribution of the macrozoobenthos species according with their trophic category. The ITI draws on the premise that the community structure can be evaluated by the feeding behaviour of the benthic invertebrates as a response to the organic matter content in the sediment or water column. There are four main organisms' categories (Word, 1980):

(1) suspension detritus feeders (such as the polychaete Owenia sp.);

(2) interface detritus feeders (as the polychaete Glycera sp.);

(3) surface deposit feeders (like Hediste or Hinia species); and

(4) subsurface deposit feeders (e.g. Capitella capitata or oligochaeta species).

With this division of the organisms in a sample, the trophic structure can be calculated using the formula:

$\mathrm{ITI}=100-33.33 \times\left(\frac{0 \times n_{1}+1 \times n_{2}+2 \times n_{3}+3 \times n_{4}}{n_{1}+n_{2}+n_{3}+n_{4}}\right)$

where $n_{1}, n_{2}, n_{3}, n_{4}$ are the number of individuals sampled in each of the above mentioned groups. The coefficient in the formula (0-3) is a scaling factor that allows the index to range gradually between 0 and 100 and to be sensitive to changes in infaunal feeding strategies. Word (1978) established that values near 100 are indicative of a majority of suspension feeders, which means that the environment is not disturbed. Values near 0 are indicative of a subsurface deposit feeder's dominance, meaning that the environment is degraded (Table 1 ).
One of the disadvantages is the difficulty in determining the organism's diet and thus attributing it to a particular trophic level. Generally, the diet, which can be observed in the stomach content or in laboratory experiments, is difficult to establish, and can vary from one population to another among the same taxonomic group. Moreover, due to geographical restrictions, the feeding behaviour of certain species can be largely influenced by their habitat conditions. For example, Caprella sp. along the European coast is considered a predator (Mancinelli et al., 1998), whereas along the American coasts exhibits suspension feeding behaviour (Word, 1990).

This index has been applied to systems such as bays (Donath-Hernàndez and Loya-Salinas, 1989) with reasonably satisfactory results. It is also important to state that ITI has a limited sensitivity to changes in abiotic and biotic components and it is not a good descriptor of system health (Maurer et al., 1999). It also presents limitations when comparisons between different geographic areas are done, since each ecosystem has its own dominant local species, which requires a specific feeding behaviour and scaling factor. The ITI index was recommended as an assessment tool for monitoring programs and it is widely used as a pollution index (Kennish, 1997). It can also be a very useful tool in management decisions (Maurer et al., 1999), although its use should suffer a critical approach.

\subsection{Macrofauna monitoring index (MMI; Roberts et al., 1998)}

The main goal of the macrofauna monitoring index (MMI) is assessing the impact of dredge oil dumping, based on monitoring indicator species in the benthic macrofauna. It is based on twelve indicator species, according to the criteria of easiness of identification, easy extraction from samples, and representativeness. Each species was rated from 1 to 10 (very intolerant to impacts) based on the density of species in control versus impacted sites. A score of 0 indicates a species, which is more common at impacted samples than at unimpacted sites. This score reflects basically the impacts that dredge spoil dumping have on its abundance. The index final score (Table 1) was obtained by the averaged sum of all the species scores. Its aim was the development of a sitespecific monitoring index that would be statistically precise, biologically meaningful and very cost effective.

According to Roberts et al. (1998), the impacted sites show a higher content in mud or fine sand presenting lower macrofaunal abundance, diversity, and richness than the unimpacted regions. This index identifies and estimates the stress and disturbance on the study site without appealing to exhaustive identification methods, since it relies on a small but informative subset of fauna. The MMI presents two main disadvantages: this index is semi-quantitative measure of the degree of impact on macrofauna, correlating strongly with macrofaunal richness and abundance (Roberts et al., 1998) and it is site and pollution type specific (Simboura and Zenetos, 2002).

\subsection{Organism sediment index (Rhoads and Germano, 1986)}

The OSI was developed to assess the BHQ in shallow water environments, allowing the evaluation of stages of organic 
pollution in the ecosystem. This index presents four main metrics (1) dissolved oxygen conditions; (2) depth of the apparent RPD; (3) infaunal successional stage; and (4) presence or absence of sedimentary methane. The successional stage was measured with sediment profile images, which characterizes the benthic habitat in relation to physical-chemical features (Rhoads and Germano, 1982). The OSI index has also been used in some studies to map habitat quality (Rhoads and Germano, 1986), to assess physical disturbances and organic enrichment (Valente et al., 1992), and to evaluate the effects of mariculture (O'Connor et al., 1989). Two recent studies showed that low values of apparent RPD were correlated with low OSI scores (Nilsson and Rosenberg, 2000).

Rhoads and Germano (1986) based their index on mean depth of the apparent RPD, the presence of gas voids, and on a visual classification of the infauna into successional stages, which could range from -10 to +11 . The lowest values are attributed to the bottom sediments with low or no dissolved oxygen, without apparent macrofauna, and with methane present in the sediment. The highest values are attributed to aerobic sediments with a deep apparent RDP, established macrofaunal communities, and without methane gas. The index classification is provided on Table 1.

\subsection{Portuguese-benthic assessment tool}

The P-BAT integrates, in a cumulative index, three widely used metrics - Shannon-Wiener index $\left(H^{\prime}\right)$, Margalef index $(d)$ and AMBI - which are based on different approaches when evaluating system status. This integration results from experience works on the Portuguese transitional and coastal waters systems that demonstrate that, when evaluating the system condition, the combination of several metrics is more accurate than single metrics. The Shannon-Wiener index is a diversity measure that takes into account the proportional abundance of species; the Margalef index is based on the specific richness of a system and the AMBI on the ecological strategies followed by estuarine organisms (indicator species). Overall index classifications have been developed for the Portuguese transitional water bodies (Table 1), in order to be integrated in the WFD as a reference measure (Teixeira et al., personal communication) and it can range between 0 (bad ecological quality) and 1 (good ecological quality).

To calculate the multimetric approach, the ShannonWiener, Margalef and AMBI values (previously calculated) were standardized by subtracting the mean and dividing by the standard deviation. Afterwards, a FA was conducted to construct a three coordinate system that was then used to derive the final station score, using as comparison the reference conditions determined for the system. These reference conditions were estimated based on two opposite situations: the best condition that a system could present (without impacts) versus the worse possible scenario for the same system (Bald et al., 2005; Muxika et al., 2007). The P-BAT index was developed with data from the Mondego estuary (Portugal) for winter conditions and using a $1 \mathrm{~mm}$ sieve.

\subsection{Pollution load index (PLI; Jeffrey et al., 1985)}

This index, based on contaminations loads, includes three parameters: (1) water; (2) fauna; (3) flora and sediment. The PLI scores individual sediment contaminants according to a log scale from baseline to threshold (Wilson, 2003). The formula is computed as:

PLI $=\operatorname{antilog}_{10}\left\{1-\left(\frac{C P-B}{T-B}\right)\right\}$

where CP is the pollutant concentration; $B$ the baseline, unpolluted; and $\mathrm{T}$ the threshold, damage. The scores for each pollutant are summed to give a total site PLI thus,

Site $\mathrm{PLI}=\left(\mathrm{PLI}_{1} \times \mathrm{PLI}_{2} \times \mathrm{PLI}_{n}\right)^{1 / n}$, for $n$ pollutants

The sites scores are then summed likewise to give the estuary index value:

$\mathrm{PLI}=\left(\mathrm{PLI}_{1} \times \mathrm{PLI}_{2} \times \mathrm{PLI}_{j}\right)^{1 / j}$, for $j$ sites

The PLI varies from 10 (unpolluted) to 0 (highly polluted). This index allows the comparison between several estuarine systems and has been applied in several geographical regions, like in Europe and US estuaries (Wilson, 2003). Caeiro et al. (2005) have highlighted the ease of implementation of this index.

\subsection{Virginia province benthic index (VPBI; Paul et al., 2001)}

This benthic index has been developed over two stages for application in the Virginia province, USA. Here we detail the most recent formulation by Paul et al. (2001) which is an expanded version of Schimmel et al. (1999). The goal of VPBI is to evaluate the benthic condition of estuarine communities, discriminating between degraded and non-degraded sites. This index is based on a measure of diversity (related with unimpacted sites) and the abundance of pollution tolerant taxa, Tubificidae, and Spionidae (related with impacted conditions). The index was developed for the U.S. EPA Environmental Monitoring and Assessment Program. The three benthic metrics in the index are: 1) salinity normalized Gleason's, D, based upon infauna and epifauna; 2) salinity normalized Tubificidae abundance; and 3) abundance of Spionidae. This index is given by:

\footnotetext{
Benthic index $=1.389 \times \frac{\text { (salinity normalized Gleason's, D, based upon infauna and epifauna }-51.5)}{28.4-0.651}$

$\times \frac{\text { salinity normalized Tubificidae abundance }-28.2}{119-0.375} \times \frac{(\text { Spionidae abundance }-20.0)}{45.4}$$$
119-0.375 \text { ormalized Gleason's, D }-0.00545 \times \text { salinity }
$$

$=0.0489 \times$ salinity normalized Gleason's, $D-0.00545 \times$ salinity
normalized Tubificidae abundance - Spionidae abundance -2.20
} 
where salinity normalized Gleason's, $D$, based upon infauna and epifauna $=$ Gleason's $\mathrm{D} /(4.283-0.498 \times$ bottom salinity $+0.0542 \times$ bottom salinity ${ }^{2}-0.00103 \times$ bottom salinity $^{3}$ ) $\times 100$ and salinity normalized Tubificidae abundance $=$ Tubificidae abundance $-500 \times \exp (-15 \times$ bottom salinity), and $\exp (. .$.$) denotes the exponential function.$

The salinity normalization for Tubificidae abundance required a different procedure than that used to normalize the other benthic metrics. Tubificidae are only observed for low salinity water with some occurrence being normal for unimpacted sites. Impacted sites would be characterized by large Tubificidae abundances. This index identifies the unimpacted sites by a negative gradient of salinity normalized abundance and the impacted sites with positive values. In this index, positive values are indicative of healthy community conditions and negative values reflect degraded communities (Table 1).

Although this index gives an overall system condition, it is important to notice that it was based on the benthic communities, so the habitat condition of the pelagic area, submerged aquatic vegetation and marshes is not assessed.

\section{Application of three broadly used indices: the Mondego estuary case study}

\subsection{Study site: Mondego estuary}

The Mondego estuary, located on the western coast of Portugal $\left(40^{\circ} 08^{\prime} \mathrm{N}, 8^{\circ} 50^{\prime} \mathrm{W}\right)$, is a warm temperate estuary with about $21 \mathrm{~km}$ long. In its terminal part the estuary is composed by two branches - North and South arms - separated by an alluviumformed island (Morraceira Island) (Fig. 1). These two subsystems present distinct hydrological characteristics. The North arm is deeper ( $5-10 \mathrm{~m}$ during high tide), presents stronger daily salinity changes (the freshwater flows basically through this arm), and the bottom sediments consist mainly of medium to coarse sand (Marques et al., 1993). This estuarine branch constitutes the principal navigation channel, supporting the harbour and city of Figueira da Foz, and is subject to constant dredging activities. On the other hand, the South arm is shallower (2-4 m during high tide), is composed mostly by sand to muddy bottoms, and until recently was almost silted up in the upstream connection to the main river course. This constraint forced the water circulation to be mainly dependent on tidal penetration and the freshwater inflow of a tributary, Pranto River, controlled by a sluice (Marques et al., 1993; Patrício et al., 2004). All these factors contribute to the strong daily temperature oscillations verified in this subsystem.

The entire estuary is under permanent anthropogenic pressures and several impacts determine its maintenance and development as a system (Marques et al., 2003). From 1997 onwards, experimental mitigation measures have been applied attempting to reduce the eutrophication symptoms in the South arm (e.g. Zostera noltii beds decline).

According to Teixeira et al. (in press) with the division of the Mondego estuary by stretches, the entire natural variability/ diversity within this system should be covered. Apart from salinity features (based on the Venice symposium classification) different habitats that might provide different possibilities for benthos to settle are accounted for. Five major stretches were considered (Fig. 1): the euhaline estuarine stretch, located near the estuary mouth and characterized by high bottom salinities; the polyhaline muddy area (with a mean bottom salinity of 27 and with similar communities features, influenced by sediment type); the polyhaline sand zone, located in the North arm; the mesohaline stretch, with a mean salinity of 14 and the oligohaline stretch (bottom salinity of 1.7). Moreover, in the Mondego estuary, the Southern and Northern arms have been described as two different subsystems (Marques et al., 1993, 2003), where the North arm has been considered as possessing benthic communities' impoverishments relative to the South arm, mainly due the higher sediment instability (Marques et al., 1993).

\subsection{Sampling and laboratorial procedures}

In August 2005, as part of the Mondego estuary survey, subtidal soft-bottom macrofauna were sampled at 25 stations

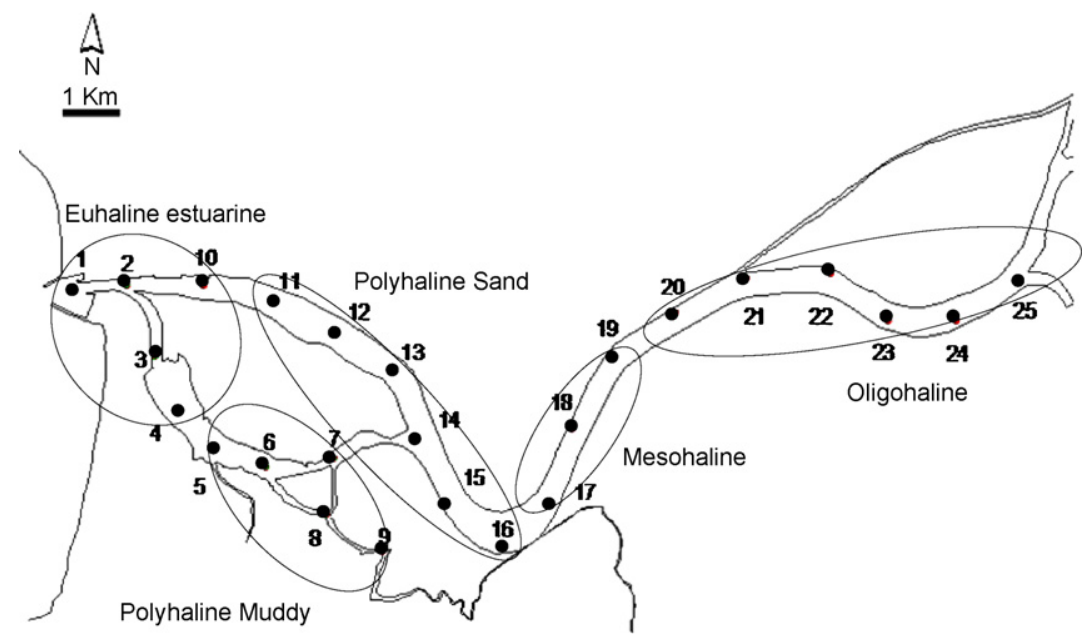

Fig. 1 - Sampling stations used in the Mondego estuary subtidal survey. Euhaline estuarine: 1-4 and 10; polyhaline muddy: 5-9; polyhaline sand: 11-16; mesohaline: 17-19 and oligohaline: 20-25. 
along the estuary (Fig. 1). Five replicate samples were randomly collected, at each station, using a van Veen LGM grab, with $0.078 \mathrm{~m}^{2}$ dredging area, immediately sieved through sieve-screen with a $0.5 \mathrm{~mm}$ mesh, and preserved within a $4 \%$ formalin solution. In the laboratory samples were washed through a series of nested sieves of 1.0 and $0.5 \mathrm{~mm}$, sorted and identified to the lowest possible category, preferentially to species level. Once identified and counted, biomass was estimated as ash free dry weight ( $\mathrm{g} \mathrm{AFDW} \mathrm{m}^{-2}$ ) by drying to constant weight at $60^{\circ} \mathrm{C}$ and ashing at $450{ }^{\circ} \mathrm{C}$ for $8 \mathrm{~h}$.

In conjunction with the macrofaunal sampling, salinity, temperature, $\mathrm{pH}$ and dissolved oxygen were measured in situ at each station to accurately characterize the overall ecosystem's condition. For chlorophyll a and total suspended solids (TSSs) measurements, a bottle of water was collected, and afterwards filtered. Analogously, a separate sediment sample was also colleted, where the organic matter content and grain size were estimated. Winter 2005 sediment samples and salinity data were considered to determine the stretches patterns consistency.

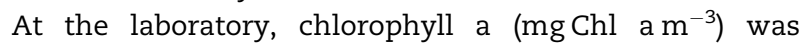
determined following the Strickland and Parsons (1972) method. The organic matter was estimated as the difference between the dry sediment sample (dried at $60{ }^{\circ} \mathrm{C}$ during $72 \mathrm{~h}$ ) and the sediment weight after its combustion $\left(450^{\circ} \mathrm{C}\right.$ for $\left.8 \mathrm{~h}\right)$. The sediment type was determined by mechanical separation in a continuous sieve column after organic matter content removal. The Brown and McLachland (1990) classification system (clay: $<0.038 \mathrm{~mm}$; silt: $>0.038$ to $<0.125 \mathrm{~mm}$; fine sand: $>0.125$ to $<0.250 \mathrm{~mm}$; mean sand: $>0.250$ to $<0.500 \mathrm{~mm}$; coarse sand: $>0.500 \mathrm{~mm}$ ) was followed and the final results were presented as the percentage of that sediment class in the total weight of the sample.

\subsection{Indices general considerations}

In order to evaluate the condition and integrity of the Mondego estuary, two indices were tested - BCI (see Section 2.3 and Table 1; Engle and Summers, 1999) and B-IBI (see Section 2.10.1 and Table 1; Weisberg et al., 1997) - and afterwards compared with the P-BAT (see Section 2.16 and Table 1), developed in the scope of WFD, in order to compare with the two other combinative indices scores. It is important to highlight that for the B-IBI application, the estuarine system had to be divided into stretches (Llansó, 2002). Teixeira et al. (in press) applied the same principles to the Mondego estuary, achieving five major areas within the estuary (euhaline estuarine, polyhaline muddy, polyhaline sand, mesohaline and oligohaline). The Llansó metrics attribution scheme was applied to most of the Mondego estuary ecosystems; however, the authors did not considered the euhaline estuarine ecosystem. The metrics and score ranges for the polyhaline sand system were used since they presented the same salinity and sediment types classifications (Table 2). The tolerance score and the percentage of Tanipodinae to Chironomidae metrics could not be applied to this case study due to the lack of information regarding the pollution tolerance capacity for most of the species. Moreover, in our data set, the Chironomidae species were all considered as a general group and were not separated.

\subsection{Data analysis}

One-way ANOVA tests were used to evaluate differences of the two sieve mesh sizes (combined $1 \mathrm{~mm}+0.5 \mathrm{~mm}$ and $1 \mathrm{~mm}$ alone) in characterizing the Mondego estuary benthic communities. Differences were evaluated for the several measured indices along the estuarine systems. The Pearson correlation analysis was calculated to evaluate the association between the several BCI parameters and the environmental variables observed in summer conditions. The environmental data (physical-chemical parameters) were previously log transformed $(\log (X+1))$ before its use to reduce heterogeneity in variance.

SIMPER analysis was undertaken (PRIMER 5.2.6 ${ }^{\circ}$ software package from Plymouth Marine Laboratory, UK), considering the entire estuarine system and the five salinity stretches defined for the Mondego estuary, in order to recognize the species allocation along the distinct estuarine habitats.

Finally, a kappa statistic was used to compare the qualitative classifications obtained by the different indices. The kappa coefficient is a widely used indicator of categorical agreement measure. This test has as main goal the assessment of the agreement on multicategory rating by two measures, classifying a sample on the same categorical scale. In order to achieve this, a square table is necessary to formulate. It was then followed the Landis and Koch (1977) classification ranges.

In order to compare the indices, a correspondence had to be made previously between the final score's classifications (Table 3).

\section{Results}

\subsection{Mesh size}

The density values (ind. $\mathrm{m}^{-2}$ ) were significantly higher for the combined ( $1 \mathrm{~mm}+0.5 \mathrm{~mm}$ ) sieve (ANOVA, $F=6.87, p=0.0117$ ). This sieve presented a density almost $64 \%$ higher than the $1 \mathrm{~mm}$ sieve. Regarding the number of taxa, significantly higher

Table 3 - Indices final classifications correspondence: Portuguese-benthic assessment tool (P-BAT), benthic condition index and benthic index of biotic integrity (B-IBI)

\begin{tabular}{ccc}
\hline P-BAT & Benthic Condition Index & B-IBI \\
\hline High & Non-degraded & Meets restoration goals \\
Good & Moderate & Marginal \\
Moderate & Degraded & Degraded \\
Poor & Severely degraded \\
Bad & &
\end{tabular}


values were also found in the combined sieve (ANOVA, $F=9.38, p=0.004)$.

Furthermore, analysis of the density results revealed higher differences between sieves in the upstream stations (Fig. 2A), while the number of taxa presented the opposite behaviour, with stronger disparities near the mouth and in the South arm of the estuary (Fig. 2B). Total biomass values were not significantly different between sieves (ANOVA, $F=0.00$, $p=0.99$ ) probably because only very small individuals are retained with the $0.5 \mathrm{~mm}$ mesh screen (Fig. $2 \mathrm{C}$ ). The retention of large and weighty individuals (e.g. green crab Carcinus maenas or bivalvia species as Cerastoderma edule and Corbicula fluminea), as well as of key species like the Isopoda Cyathura carinata and the gastropoda Hydrobia ulvae, provided a balanced relation for the loss of the abundant but tiny individuals captured by the $0.5 \mathrm{~mm}$ screen. In August 2005, the subtidal communities appear to be relatively diverse and moderately abundant in the main river course (North arm). Despite presenting lower density values, the stretches corresponding to the South arm and estuary mouth showed higher number of species (taxa), suggesting a more balanced community structure (Table 4).

To obtain a full understanding of the differences between sieves a retention efficiency rate was calculated. Retention efficiency is the proportion of organisms retained in the $1 \mathrm{~mm}$ sieve compared with the densities found in the combined sieve (Schlacher and Wooldridge, 1996). At species level, sieving losses were especially notorious for all species usually
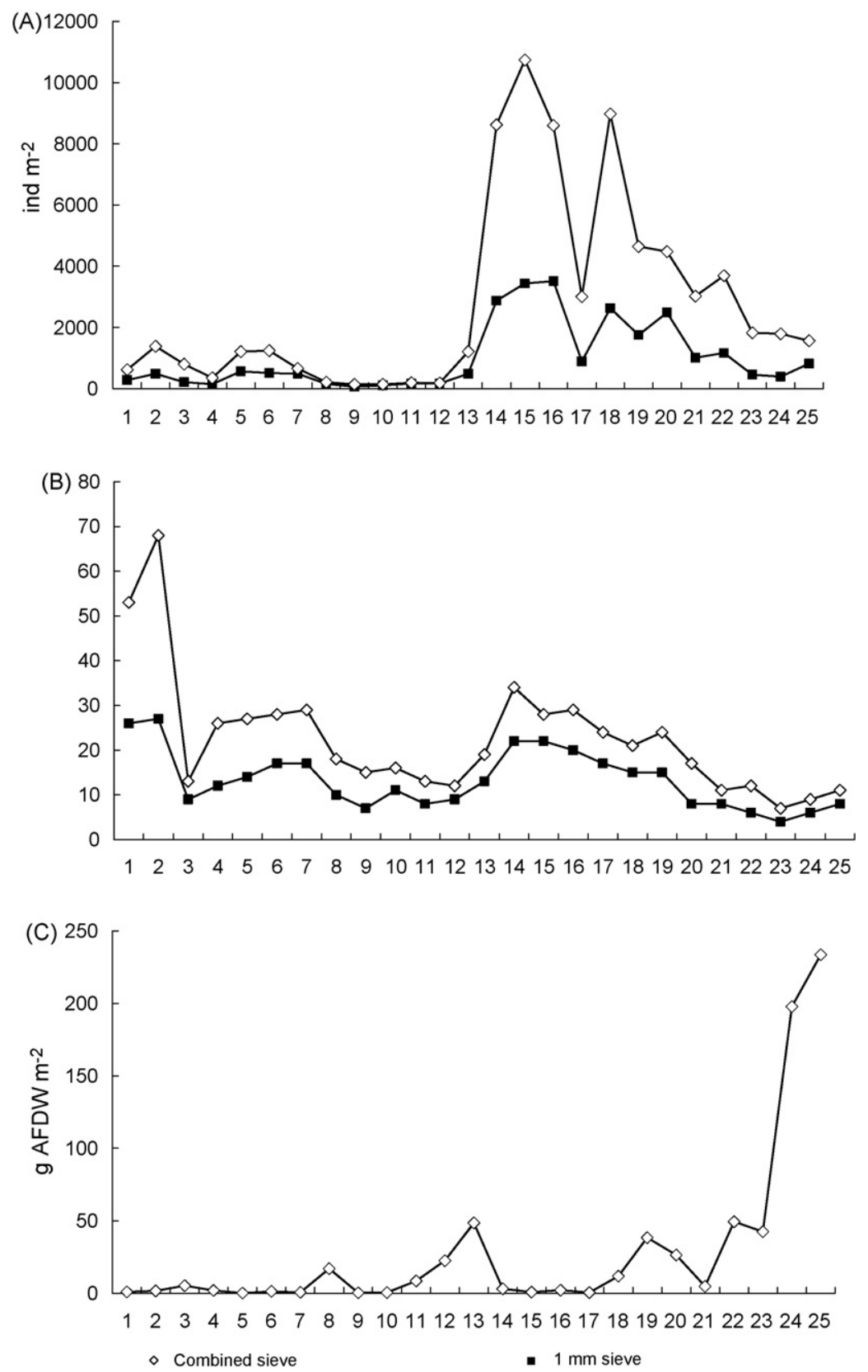

Fig. 2 - Macrofaunal density (A), number of taxa (B), and macrofauna biomass (C) using the 1 mm and the combined sieves $(1 \mathrm{~mm}+0.5 \mathrm{~mm})$, along 25 estuarine stations, in summer 2005 . 
Table 4 - Number of taxa and mean ( \pm standard deviation) species density (ind. $\mathrm{m}^{-2}$ ) in the estuarine stretches, in summer 2005

\begin{tabular}{|c|c|c|c|c|}
\hline & \multicolumn{4}{|c|}{ Sieve } \\
\hline & \multicolumn{2}{|c|}{$1 \mathrm{~mm}$} & \multicolumn{2}{|c|}{ Combined } \\
\hline & No. of taxa & Density & No. of taxa & Density \\
\hline Euhaline estuarine & 51 & $24.3( \pm 45)$ & 104 & $31.8( \pm 78.7)$ \\
\hline Polyhaline muddy & 28 & $63.9( \pm 147.9)$ & 51 & $68.1( \pm 163.8)$ \\
\hline Polyhaline sand & 40 & $266.4( \pm 662.3)$ & 57 & $518.7( \pm 1950.6)$ \\
\hline Mesohaline & 22 & $239.7( \pm 620.3)$ & 35 & $475.2( \pm 2000.8)$ \\
\hline Oligohaline & 15 & $422.7( \pm 942.8)$ & 29 & $564.9( \pm 1558.2)$ \\
\hline Total estuary & 81 & $312.3( \pm 963)$ & 145 & $478.3( \pm 2364.4)$ \\
\hline
\end{tabular}

highly abundant in subtidal ecosystems, such as polychaeta (e.g. Autolytus sp., Mysta picta,), amphipoda (e.g. Atylus falcatus, Pontocrates altamarinus), and small Isopoda species (e.g. Zenobiana prismatica). Regarding this, retention efficiency rate was calculated for the $1 \mathrm{~mm}$ sieve considering higher taxonomic groups (polychaeta, bivalvia, amphipoda, decapoda, isopoda, gastropoda, oligochaeta, other crustacea, other groups). The density values of the two sieves fractions were compared through a one-way ANOVA analysis. This test revealed that only the polychaeta and bivalvia groups were significantly underestimated and presented significant losses between the two sieves (ANOVA $_{\text {Poly }}, F=4.10, p=0.0486$; ANOVA $\left._{\mathrm{Biv}}, F=5.32, p=0.0254\right)$. Analysing the density patterns in the two sieves, visible changes in the community structure composition were verified. This trend can be partially explained by the low retention capacity of juvenile forms and smaller organisms using the $1 \mathrm{~mm}$ sieve alone. For example, half of the total bivalvia density was lost with the
$1 \mathrm{~mm}$ sieve, mainly due to the juveniles' forms of C. glaucum, $S$. plana, and C. fluminea.

\subsection{P-BAT}

The main goal of applying this methodology in the present work was to use this metric value as a reference classification to validate the results obtained by the two tested indices (BCI and B-IBI). Analysing the P-BAT final results, using both sieves, was possible to observe that there were some classification disparities. According to this index, the final estuarine condition assessment ranged between Moderate and High classifications in both sieves. In the $1 \mathrm{~mm}$ sieve $92 \%$ of the stations presented a High or Good ecological status. This value suffered a slight decrease for the combined sieve, where $16 \%$ of the stations presented Moderate conditions. The classification differences observed for both sieves were near $30 \%$, corresponding to 7 stations from a total of 25 (Table 5) (Fig. 3).

Table 5 - Benthic condition index (BCI), benthic index of biotic integrity (B-IBI), Portuguese-benthic assessment tool (PBAT) final scores and classifications, using the two sieves (1 $\mathrm{mm}$ and combined sieves), along the 25 estuarine station, in summer 2005 (white: non-degraded; grey: moderate; and black: degraded)

\begin{tabular}{|c|c|c|c|c|c|c|}
\hline \multirow{2}{*}{ Stations } & \multicolumn{3}{|c|}{ Combined sieve } & \multicolumn{3}{|c|}{$1 \mathrm{~mm}$ sieve } \\
\hline & $\mathrm{BCl}$ & $\mathrm{B}-\mathrm{IB|}$ & P-BAT (adj.) & $\mathrm{BCl}$ & B-|B| & P-BAT \\
\hline ST1 & 9.7 & 2.7 & 0.90 & 9.5 & 2.7 & 0.88 \\
\hline ST2 & 7.2 & 2.3 & 0.90 & 6.3 & 2.3 & 0.79 \\
\hline ST3 & 2.6 & 3.0 & 0.52 & 5.4 & 3.0 & 0.66 \\
\hline ST4 & 5.9 & 3.0 & 0.67 & 5.0 & 2.7 & 0.66 \\
\hline ST5 & 4.7 & 2.0 & 0.55 & 4.1 & 2.3 & 0.54 \\
\hline ST6 & 3.6 & 2.3 & 0.63 & 3.1 & 2.0 & 0.67 \\
\hline ST7 & 7.8 & 1.7 & 0.73 & 8.7 & 2.3 & 0.73 \\
\hline ST8 & 3.2 & 2.3 & 0.62 & 2.7 & 2.3 & 0.62 \\
\hline ST9 & 5.0 & 2.3 & 0.59 & 4.3 & 2.3 & 0.56 \\
\hline ST10 & 4.6 & 1.7 & 0.51 & 3.7 & 1.7 & 0.51 \\
\hline ST11 & 3.4 & 2.3 & 0.67 & 3.7 & 2.3 & 0.63 \\
\hline ST12 & 2.4 & 2.3 & 0.57 & -0.8 & 2.3 & 0.52 \\
\hline ST13 & 4.7 & 2.3 & 0.67 & 1.9 & 2.3 & 0.64 \\
\hline ST14 & 1.6 & 1.7 & 0.78 & 1.4 & 2.0 & 0.76 \\
\hline ST15 & 1.9 & 2.0 & 0.65 & 2.2 & 2.0 & 0.73 \\
\hline ST16 & 2.1 & 2.3 & 0.65 & 3.9 & 2.3 & 0.72 \\
\hline ST17 & 1.1 & 2.3 & 0.88 & 6.4 & 2.3 & 0.94 \\
\hline ST18 & 1.3 & 2.3 & 0.73 & 3.6 & 3.0 & 0.77 \\
\hline ST19 & 3.4 & 2.0 & 0.99 & 7.9 & 2.3 & 0.88 \\
\hline ST20 & 6.1 & 3.5 & 0.83 & 4.6 & 4.0 & 0.69 \\
\hline ST21 & 8.3 & 3.5 & 0.77 & 7.6 & 3.5 & 0.75 \\
\hline ST22 & 8.0 & 2.5 & 0.69 & 8.4 & 3.5 & 0.69 \\
\hline ST23 & 2.9 & 2.0 & 0.52 & 4.9 & 2.0 & 0.56 \\
\hline ST24 & 1.9 & 2.0 & 0.52 & 4.3 & 2.0 & 0.60 \\
\hline $\mathrm{ST} 25$ & 3.5 & 2.0 & 0.66 & 2.7 & 2.0 & 0.69 \\
\hline
\end{tabular}

Please cite this article in press as: Pinto, R. et al., Review and evaluation of estuarine biotic indices to assess benthic condition, Ecol. Indicat. (2008), doi:10.1016/j.ecolind.2008.01.005 


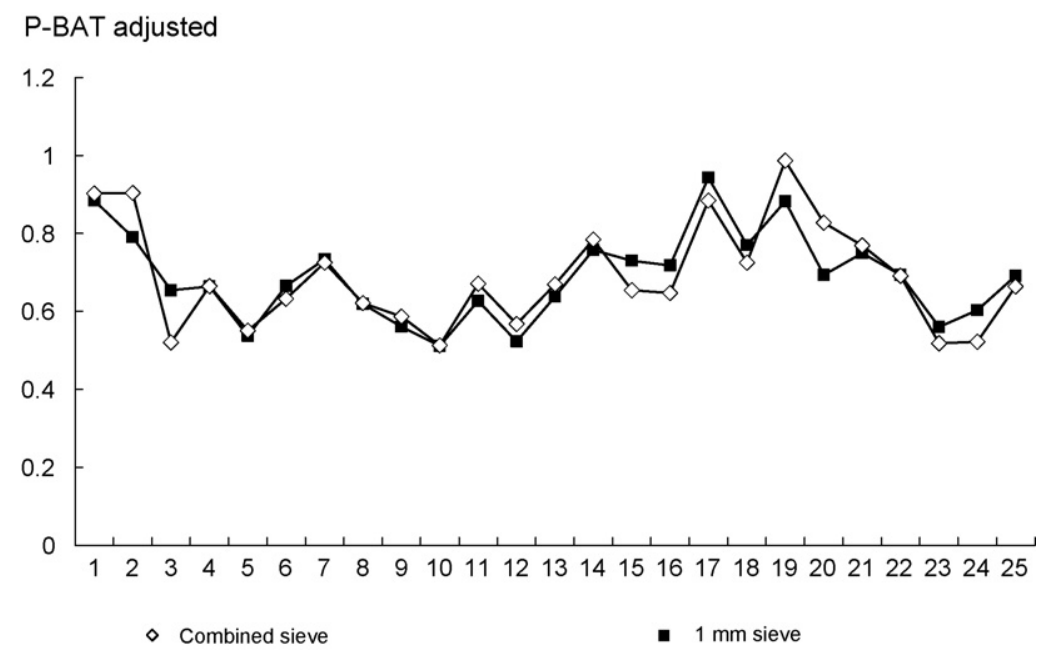

Fig. 3 - P-BAT performance for the $1 \mathrm{~mm}$ and the combined sieves in summer 2005.

\subsection{Benthic condition index}

The five BCI metrics (Shannon-Wiener diversity index adjusted to salinity, mean Tubificidae abundance and Capitellidae, bivalvia and amphipoda percents) were individually calculated and integrated in Eq. (6) in order to calculate the overall index score for each station, using two different density data sets: the $1 \mathrm{~mm}$ mesh screen and the combined sieve (Table 5). In the Mondego estuary, using the $1 \mathrm{~mm}$ sieve, the $\mathrm{BCI}$ ranged between -0.78 and 9.5. The higher values were achieved mainly by the euhaline estuarine stations (except station 10), the mesohaline (except station 18) and two oligohaline stations (21 and 22). In summary, 24\% (six stations) of the stations were classified as degraded and $36 \%$ (nine stations) as non-degraded.

In the combined sieve the values presented a variation between 1.13 and 9.66. Using this sieve, eight stations were classified as non-degraded: two in the South arm (polyhaline muddy stretch) (stations 7 and 9), three of the oligohaline stretch (20-22) and three of the euhaline estuarine (1, 2 and 4).
As so, $36 \%$ (9) of the stations were classified as degraded, while $32 \%$ (8) presented a good environmental quality.

Comparing the index performance between the sieves final classifications, some changes are perceived since $48 \%$ of the final index scores were not consistent (12 stations). The differences between the two sieves were noticeable and there were two cases where the given classification was extreme, in stations 3 and 17, classified as non-degraded by the $1 \mathrm{~mm}$ sieve and as degraded by the combined sieve. From an overall perspective better system conditions were achieved using the $1 \mathrm{~mm}$ sieve alone. Nineteen stations were considered as having good or moderate status, while with the combined sieve there were 16 stations with the same classification.

Correlation analyses were performed in order to evaluate the index submetrics that suffered greater influence from the environmental variables (Table 6). Some differences were found analysing the relation between individual metrics in the two sieves and environmental variables. These differences were mainly in the percent of Capitellidae and bivalvia

Table 6 - Significant Pearson correlation coefficients between the benthic condition index (BCI) metrics and environmental parameters, using the $1 \mathrm{~mm}$ and combined sieves $\left(N=25 ; p<0.05 ;{ }^{*} p<0.01\right)$, in summer 2005

Environmental variables

\begin{tabular}{|c|c|c|c|c|c|c|c|c|c|}
\hline BCI & \multicolumn{2}{|c|}{$\mathrm{H}^{\prime}$} & \multicolumn{2}{|c|}{ Tubificidae } & \multicolumn{2}{|c|}{ Amphipoda } & \multicolumn{2}{|c|}{ Capitellidae } & Bivalvia \\
\hline Comb $1 \mathrm{~mm}$ & Comb & $1 \mathrm{~mm}$ & Comb & $1 \mathrm{~mm}$ & Comb & $1 \mathrm{~mm}$ & Comb & $1 \mathrm{~mm}$ & Comb $1 \mathrm{~mm}$ \\
\hline
\end{tabular}

$\mathrm{pH}$

Salinity

$\mathrm{O}_{2}(\%)$

$\mathrm{Chl} \mathrm{a}\left(\mathrm{mg} \mathrm{m}^{-3}\right)$

SST

POM

Coarse sand (\%)

Medium sand (\%)

Fine sand (\%)

Silt $(\%)$

Clay (\%)

Organic matter (\%)

$\begin{array}{lllll}-0.42 & -0.55 & -0.43 & -0.43 & -0.48\end{array}$

$-0.40-0.41$

$0.63^{*} \quad 0.64^{*}$

$-0.46 \quad-0.47 \quad 0.70^{*}$

0.48

$0.70^{*}$

$0.62^{*}$

$0.83^{*}$

$0.74^{*}$

$0.88^{*}$ 
associated with environmental factors. Using the combined sieve, it was possible to observe that there was a strong positive correlation between sediment type and its organic matter content and the abundance of Capitellidae. This relation was not captured when using the $1 \mathrm{~mm}$ mesh screen alone. Although the original benthic index components were not correlated with salinity (the only factor correlated was the diversity index and it was adjusted to this variable deviation in the index development), this was not verified for the Mondego estuary. In this case study, three variables were naturally correlated with salinity (Tubificidae abundance and amphipoda percent in both sieves, and bivalvia percent in the combined sieve). All the other index submetrics did not present significant correlations with environmental parameters. In the Mondego estuary there were several factors significantly correlated with natural variables mainly with the combined sieve.

\subsection{Benthic index of biotic integrity}

The B-IBI results were obtained through the adequate scoring criteria average, according to the estuarine area under study (Table 5). Accordingly, the values for the combined sieve ranged between 1.7 and 3.5 . 36\% of the Mondego estuary stations were considered as severely degraded, $40 \%$ as degraded, and only $24 \%$ as meeting restoration goals or marginal (4 and 2, respectively). Nevertheless, the index performance was also tested using the $1 \mathrm{~mm}$ sieve alone and the B-IBI presented values between 1.7 and 4 , classifying $28 \%$ of the stations as severely degraded, $44 \%$ as degraded, $8 \%$ as marginal, and $20 \%$ as meeting restoration goals.

Through sieve comparison, $28 \%$ of the stations (corresponding to seven stations) showed dissimilarities in the final B-IBI classifications. The polyhaline sand stretch was the estuarine zone that presented a higher classification consistency within sieves, with all the stations presenting the same classification. In contrast, the polyhaline muddy was the estuarine area that presented higher differences between sieves, where three stations from five, presented dissimilar classifications. At station 18, opposite conditions were achieved, being classified as non-degraded by the $1 \mathrm{~mm}$ sieve whereas the combined sieve provided a degraded status.

\subsection{Biotic indices comparative approach}

The samples were sieved through two sizes of meshes to determine the effect of sieve size on the indices final scores and classifications. At station 3, worse environmental conditions are observed when using the combined sieve with the PBAT and benthic index. Nevertheless, this change was not captured by the B-IBI. The SIMPER analysis concerning this station showed that $90 \%$ of the community density is attained by two species: Pisione remota and Glycera trydactila. Even so, and despite the $58.5 \%$ dissimilarity average between sieves, it was not possible to determine the discriminant species, due to the low number of replicates. The effect of screen size on sampling variability was not statistically significant for all tested indices (ANOVAP-BAT, $F=0.07, p=0.796$; ANOVA $_{\mathrm{BCI}}$, $F=0.23, p=0.631 ;$ ANOVA $_{\mathrm{B}-\mathrm{IBI}}, \mathrm{F}=0.74, p=0.394$ ).

Having in mind that the P-BAT methodology results were considered as reference in this study, it is possible to observe that the BCI classified 36\% (9 stations) accurately, while the BIBI classified correctly only $12 \%$ out of the 25 stations of the Mondego estuary, concerning the combined sieve. Using the $1 \mathrm{~mm}$ mesh screen the classification agreement was of $40 \%$ for the benthic index and $20 \%$ for the B-IBI. In order to test the statistical robustness of the comparison a kappa analysis was applied. This test provides a measure of agreement among the several indices classifications (Table 7). From this analysis, it was possible to observe that the P-BAT and B-IBI indices gave the most constant classification between sieves (moderately similar using the combined or the $1 \mathrm{~mm}$ sieve). The BCI classification was fairly similar between sieves, suggesting a higher sensitivity among the caught number of taxa and density patterns. Considering the agreement level between sieves for the three measured indices, significant agreement exist between the $1 \mathrm{~mm}$ and combined sieves, leading us to accept the assumption that there is agreement between sieve classifications (the null hypothesis of the kappa statistic relies on this premises and a significant $p$ value was achieved for Mondego estuary case study). It is also important to highlight the case where a negative (poor agreement level) kappa coefficient score was achieved in the combined sieve (P-BAT$\mathrm{B}$-IBI). These cases are extremely rare and only happen when the two observations agree less than would be expected just by chance. When comparing the reference measure (P-BAT) with the newly tested indices no significant classifications agree-

Table 7 - Kappa analysis coefficients for the indices applied to the Mondego estuary, following the kappa coefficient classification, following Landis and Koch (1977) classification (P-BAT, Portuguese-benthic assessment tool; BCI, benthic condition index; B-IBI, benthic index of biotic integrity)

\begin{tabular}{llcccc} 
& & Kappa coefficient & Standard error & $p$-Value & Agreement level \\
\hline Sieves comparison & P-BAT sieves & 0.448 & 0.168 & 0.0025 & Moderate \\
& BCI sieves & 0.284 & 0.147 & 0.0405 & Fair \\
& B-IBI sieves & 0.591 & 0.129 & 0.000 & Moderate \\
1 mm sieve & P-BAT-B-IBI & 0.002 & 0.058 & 0.9757 & Slight \\
& P-BAT-BCI & 0.124 & 0.085 & 0.1129 & Slight \\
Combined sieve & B-IBI-BCI & 0.058 & 0.094 & 0.531 & Slight \\
& P-BAT-B-IBI & -0.042 & 0.066 & 0.4798 & Poor \\
& P-BAT-BCI & 0.107 & 0.079 & 0.2373 & Slight \\
& B-IBI-BCI & 0.084 & 0.098 & 0.371 & Slight \\
\hline
\end{tabular}


ments were achieved, since the kappa coefficient was very low, thus suggesting low agreements among indices.

\section{Discussion}

\subsection{Mesh size}

One of the goals of the current study, in order to evaluate the $\mathrm{BCI}$ and B-IBI performance, was to determine to what extent the main source of sampling variation - specifically mesh size - affects the accuracy and precision of benthic communitybased indices calculation. The $0.5 \mathrm{~mm}$ mesh, which was the finest screen tested, was chosen as reference measure for comparison with a coarser screen $(1 \mathrm{~mm})$ mainly because the $\mathrm{B}$-IBI and BCI assumptions require samples collected with the combined sieve. Although certain indices (e.g. ITI, Word, 1980) postulate that single $1 \mathrm{~mm}$ sieve benthic samples, properly taken and screened, are entirely adequate for benthic macrofauna evaluation, we consider important the use of the $0.5 \mathrm{~mm}$ mesh screen. This sieve captures small-sized species, usually indicators of degraded conditions, as well as juvenile forms, providing a more accurate and precise benthic macrofauna assemblage composition, and, so, evaluation. However, the sieve aperture depends on the study objective. According to Schlacher and Wooldridge (1996) if the goal is to characterize a benthic community structure, a smaller mesh aperture is required, whereas, for pollution impact assessments coarser screens (e.g. $1.0 \mathrm{~mm}$ ) are sufficient. Nevertheless, these results demonstrate that samples processed with coarser sieves were less rigorous in evaluating the benthic communities' dynamics and composition. This is especially important when population density and taxa occurrence have a stronger influence on benthic status evaluation. For example, considering indices as B-IBI, where the species are formerly grouped into specific classifications (epifauna-infauna; trophic group and ecological behaviour) the overall system classification can dramatically change if we only use the larger organisms. Word (1980) suggested the use of screen sizes that will filter out the numerous smaller individuals so that the abundances of these taxa are more nearly comparable to the larger species. Nevertheless, indices as AMBI, in the P-BAT, or B-IBI include specific metrics that account for the abundance and occurrence of such groups and so are more susceptible of changes using one or another sieve. These situations can lead to misinterpretations of results since both abundances are not comparable and species proportions can affect the overall community assessment.

\subsection{Benthic condition index}

A response indicator like the BCI provides a numerical quantification of the benthic communities' adaptations to environmental stresses (Engle, 2000). Although the benthic index was designed to range between 1 and 10, for the Mondego estuary there was a case where a negative value was obtained (station 12: benthic index score $=-0.78$ ) for the $1 \mathrm{~mm}$ sieve. According to Engle and Summers (1999), this can only happen when the new local conditions are much more degraded than the conditions of the places for where the index was developed and applied, suggesting that this station presented benthic conditions substantially more degraded than the original test sites used to develop the index. The fact that only negative values were achieved with the $1 \mathrm{~mm}$ sieve can possibly be explained by the fact that fewer organisms were captured which implies a change in community composition. The combination of these factors could have promoted the increase of one of the metrics and consequently the decrease of the $\mathrm{H}^{\prime}$ diversity index. Interestingly, when both sieves were compared in this station, the Shannon-Wiener index presented higher values in the combined sieve. This fact, together with the decrease of bivalves dominance, suggests that, in cases strongly dominated by one species, the $1 \mathrm{~mm}$ sieve can attribute a higher role to that species in the community, than the one it really has, and the final ecosystem assessment result is influenced.

According to Engle and Summers (1999), the main strength of this indicator lies in the checks and balances associated with combining these metrics. This assumption is reinforced by the disparities of the sieve's classifications where it was possible to confirm the non-redundancy index results. Depending on the station and variables associated to it (e.g. sediment type or water column factors) the submetric that drives the final index scores was different.

Nevertheless, it is important to highlight the strong correlations observed between the benthic index components and the environmental parameters. According to Engle and Summers (1999) one of the strong points of this index is the lack of significant correlations with any natural habitat factor, like salinity or sediment type. This was addressed during the index development by adjusting any benthic parameter that was correlated with these factors. Regarding the Mondego estuary, this lack of significant correlations with environmental parameters was not observed. In fact, this may be related with the results obtained, especially with the combined sieve. Correlation analyses demonstrated that all variables were at some degree related to environmental factors. All these results suggest the index coefficients inadequacy for application on the Mondego estuary system. Correlation and accurate factors should be estimated for this specific system in order to obtain a stronger refinement and viability of the index to assess its benthic condition and status. In fact, Engle (2000) cautions the application of the index outside of the biogeographic region for where it was designed since the environmental stresses affecting the benthic communities in Gulf of Mexico estuaries may differ from those affecting other regions.

\subsection{Benthic index of biotic integrity}

The B-IBI was not able to distinguish between areas and main causes of stress in the Mondego estuary subtidal communities. Among the possible reasons for the observed lack of sensitivity and robustness may be the chosen tested metrics. According to Alden et al. (2002), four metric groups proposed by Weisberg et al. (1997) proved to be significantly important to distinguish degraded from reference sites (diversity, productivity, species composition, and trophic composition). Nonetheless, for this particular case three submetrics seem to be the most important: pollution indicative taxa, pollution sensitive taxa, 
and diversity. The subsurface deposit feeders species are considered the trophic group most likely to develop pollution tolerance (Gaston et al., 1998), since they inhabit tubes or burrow beneath the sediment surface (Pinn and Robertson, 2003). In the euhaline estuarine stations there was a relative increase of these species, followed by a diversity $\left(H^{\prime}\right)$ increase and a decrease of the percentage abundance of pollution sensitive species. In this case study an important feature was recognized during the scoring attribution that can be a major drawback for accurate application and performance of the index. The scoring attribution of 1, 3, or 5 values does not allow a continuous variation quantification of the submetrics. In other words, it does not allow the gradient perturbation continuum determination since, in this case, if two submetrics were up and one down the final index result will be a better system condition achievement, minimizing an important metric as the relative reduction of species sensitive to pollution. Ott (1978) denominated this feature as eclipsing, where one good overall value can mask a low value for a particular component. Moreover, for the polyhaline muddy stretch the same situation occurred at station 6 , where the percentage abundance of carnivore/omnivore specimens decrease (that promoted the worsening status of the two adjacent stations -5 and 7) was masked by the diversity and total abundance increase. Similar observations were also stated for freshwater systems, where Blocksom (2003) found that a scoring method using continuous scaling worked better than such a point scaling, being included in posterior IBI like indices development for streams (Böhmer et al., 2004). The carnivore/omnivore species abundance percentage was one of the main index components that promoted the final stations classifications differences between sieves, especially on the meso- and oligohaline estuarine stretches. The main factor contributing to this occurrence was the retention of large sized organisms that are mainly captured by the $1 \mathrm{~mm}$ sieve. When adding the total abundance captured by the $0.5 \mathrm{~mm}$ screen these species become less abundant and so lose some of their weight in trophic assessments. Once more, it is illustrated that the $1 \mathrm{~mm}$ sieve masks the real system structure, by attributing a stronger role to species that become less dominant when more precise population estimation is obtained.

Our results for the Mondego estuary are concordant with several attempts to apply the estuarine B-IBI to other systems geographically close to Chesapeake Bay that were not successful (e.g. Delaware Bay, Long Island Sound, HudsonRaritan estuary), with fidelities of less than 50\% (Engle and Summers, 1999). The $20 \%$ station classification agreement among the B-IBI and P-BAT reference classification was confirmed by the poor agreement level achieved by the kappa analysis for the combined sieve. This statistical test determines the coefficient of agreement without being obfuscated by chance agreement, as happens when analysing the percentage of times two situations agree (Carletta, 1996). The indices comparison provided a negative agreement rate suggesting a concordance level below the one obtained by mere chance, what only revealed the low accuracy and strength of such an index applied to systems other than the one for where it was designed. This does not mean, however, that a B-IBI index cannot be developed for those systems, but each application must be specifically developed for the system in question; thus re-parameterizing the reference measures used for comparison and scoring attribution for each estuary. This has been already stated for freshwater environments (Seegert, 2000), where it is considered that even between identical ecoregions or faunas some fine metrics and/or scoring tuning have to be done.

\subsection{Biotic indices comparative approach}

In the Mondego estuary case study, when the combined sieve was used the indices presented a decrease in environmental conditions at the polyhaline sand stations. On the other hand, the euhaline estuarine area presented the best environmental conditions according to all tested metrics. These results were influenced by the species occurring on that part of the system. For example, these stations exhibited high species density such as Owenia fusiformis or Lanice conchilega, known by their sediment stabilising behaviour through tube formation binding the sand grains together (Schroeder, 2003). At station 3, the final P-BAT reflected a strong difference between the $1 \mathrm{~mm}$ and combined sieves. The combined sieve benthic index final scores also reflected these results, where there was a high increase of tubificids (ecological group V) in relation to the $1 \mathrm{~mm}$ sieve. These results suggest a possible impact in the estuarine area such as recent interventions to create a small harbour. However, more studies would be necessary to confirm this hypothesis. Nevertheless, this trend is not reflected on the B-IBI scores, where good environmental conditions are achieved. This station results confirm previous observations for the B-IBI system classification methods, since the reference measures used for scoring attribution are not the ideal for this system. Several changes in the metrics are not recognized; for example the high increases of the SsDF or total abundances, for the standard stretch measures.

The differences in approach and suites of measures that are included in the different benthic indices lead naturally to questions about whether their application yields dissimilar results. When comparing the indices performance it is possible to observe that, despite the low indices resolution and patchy classifications, the combined sieve presented more significant agreements than the $1 \mathrm{~mm}$ mesh screen solely. Once more, the sensitivity and robustness of the combined sieve determines the overall system classification. Likewise, it was expected a significant correlation among the P-BAT-B-IBI indices since they are all based on the benthic species classification concept according to their sensitiveness along a gradient of increasing organic matter content. Additionally, no other significant agreement cases were obtained for the B-IBI index, which suggests that this index was the one that responded worse. Despite all the differences obtained among indices, the overall trend is similar: the euhaline estuarine stations presented higher ecological status, along with the first oligohaline stations. For the remaining estuarine stations patchy classifications were obtained.

The costs and time required to process, identify and analyse the organisms through a $0.5 \mathrm{~mm}$ sieve are normally three times those that would have been expended on a $1 \mathrm{~mm}$ sieve only. The $0.5 \mathrm{~mm}$ sieve effect on communities' analysis 
was to push the final indices scores toward a worsening of environmental conditions for the P-BAT, BCI and B-IBI values $(16,28$, and $20 \%$, respectively). Indices as the B-IBI that depend on ecological behaviour and characteristics of single species may be markedly changed by the $0.5 \mathrm{~mm}$ sieve usage not only due to the small size of the captured species but also due to the retention of larger species with the $1 \mathrm{~mm}$ sieve. From these three multimetric indices the benthic index was the index that showed more sieve variations, contrarily to the P-BAT that presented a more constant behaviour among sieves. The severe differences observed among indices suggest, nevertheless, the need for calibration and refinement of the indices criteria for this particular system.

The tested indices (B-IBI and BCI) did not correctly evaluate the Mondego estuary benthic communities' status. The main disadvantages presented by these indices' application can be summarised as:

(1) lack of specific reference values that could serve as basis for comparisons between degraded and non-degraded sites (for the B-IBI were used the values defined for the Chesapeake Bay system and those scores were too high for the Mondego estuary conditions);

(2) uncertainty regarding the species allocation into feeding guilds needed for the B-IBI metrics calculation, due to unknown or flexible species strategies;

(3) benthic index assumptions associated with scaling coefficients in the index formula (originally determined through DA) that should be based on the verified associations between the index and the main environmental factors, for this particular system.

Moreover, following Seegert (2000) the IBI metrics or metric scoring criteria transferability from one watershed to another should not be done without the respective recalibration. According to Costanza (1996) two estuarine assemblages with different taxa may be functionally similar due to the high inherent functional diversity. However, absent or rare key species produce remarkable differences in patterns. According to Jenkins et al. (2007) there are several common features between the western and eastern Atlantic coasts regarding the sediment stabilizing processes (e.g. seagrass beds, tube building polychaetes). Nonetheless, the two coasts present severe differences when comparing the habitat mosaics sedimentary formation, mostly in the absence of rarity of large digging predators or large bioturbators. All these features, combined with distinct pressures from the surrounding environments, can lead to major differences between systems and ultimately to the straightforward inhibition and unfeasible application of indices developed for one specific region to another.

Additionally, according to Engle (2000), the attributed scores and metrics for the benthic index were developed based on DA for a specific geographic region and this classification was based on contaminant values, but in most of the cases did not enter with eutrophication indicators. During the 1990s the Mondego estuary exhibited eutrophication symptoms (Marques et al., 1993) and consequently the coefficient determination should have included dissolved oxygen, giving less importance to the contaminants effects that are not a major problem in this system (Vale et al., 2002; Pereira et al., 2005).

Moreover, the multimetric system presents one major limitation that inhibits its universal application: the reference and degraded sites specification (Fausch et al., 1990) that differentiates the natural impairments from the induced ones, where it is considered that the reference sites present higher abundance and diversity of species occurring deeper in sediment and a more diverse distribution of benthos into feeding guilds (Weisberg et al., 1997). According to Eaton (2001), this kind of biocriteria has only been designed to differentiate impacted from non-degraded sites. However, what most water quality managers need is a tool that will tell them the degree of degradation of the biological community. Furthermore, despite their ability to determine a problem presence they are not nearly as effective at determining the cause of the impairment (Engle et al., 1994). Broeg and Lehtonen (2006) recommended the use of such integrated indices as tools to direct further actions in the attempt to resolve the observed differences.

Even so, some positive aspects may be enumerated from these indices application. The main one comes from the B-IBI assumption and is related to system and habitat reference conditions and classifications principles. This index considers the several estuarine stretches as individual ecosystems and establishes proper reference values for each. This may allow the correct classification of stretches since it was not accurate to evaluate in the same standard marine habitats to almost freshwater systems, since significant differences in number of taxa and abundance naturally occur. This approach has also been considered for the P-BAT application (Teixeira et al., in press) for the Mondego estuary. In addition, once designed for this system, these indices may allow the integration into a single numerical measure, several important parameters that reflect the Mondego estuary ecological condition, giving an integrated insight of the overall system processes. Moreover, both (B-IBI and BCI) are easy to understand and have a relative straightforward application, which make them interesting tools for water quality management decisions.

\section{General conclusions}

Although a single index may provide a good overview of the status of benthic environments, a universal index that works in all systems or even in systems of the same ecological type, however, is unfeasible, since benthic communities are complex and geographically diverse (Engle and Summers, 1999; Dauvin et al., 2006). Nevertheless, the use of several indices is always advised in order to get a better evaluation of the benthic community health and preferentially in association with other parameters (Salas et al., 2006; Carvalho et al., 2006). The two tested combinative indices (BCI and B-IBI) were unable to give a consistent classification for the Mondego estuary, throughout a range of water qualities, salinities and habitat types. Even so, it is believed that, with the correct reference and formulae coefficients changes, these indices could be possible tools in assessing benthic quality conditions, for this specific geographic region. 


\section{Acknowledgments}

The present study was carried out in the scope of the research projects WADI-sustainable management of Mediterranean coastal fresh and transitional water bodies: a socio-economic and environmental analysis of changes and trends to enhance and sustain stakeholders benefits (Proposal/Contract no. 015226), EFICAS-effects of natural stress generated by freshwater discharges in the benthic invertebrate estuarine communities and its influence on the assessment of the benthic ecological status (POCI/MAR/61324/2004), and RECONNECT project (PTDC/MAR/64627/2006). It was also supported by IMAR/FLAD Grants program from Luso-American Foundation. It was also supported by the FCT (Portuguese National Board of Scientific Research) through two grants (SFRH/BPD/26604/2005 and SFRH/BPD/20707/2004). Thank you to all colleagues that have contributed for this study, namely through valuable field and laboratory work.

\section{R E F E R E N C E S}

Alden III, R.W., Dauer, D.M., Ranasinghe, J.A., Scott, L.C., Llansó, R.J., 2002. Statistical verification of the Chesapeake Bay benthic index of biotic integrity. Environmetrics 13, 473-498.

Bald, J., Borja, A., Muxika, I., Franco, J., Valencia, V., 2005. Assessing reference conditions and physico-chemical status according to the European Water Framework Directive: a case-study from the Basque Country (Northern Spain). Mar. Pollut. Bull. 50, 1508-1522.

Bergen, M., Cadien, D., Dalkey, A., Montagne, D.E., Smith, R.W., Stull, J.K., Velarde, R.G., Weisberg, S.B., 2000. Assessment of benthic infaunal condition on the mainland shelf of Southern California. Environ. Monit. Assess. 64, 421-434.

Blanchet, H., et al., 2007. Use of biotic indices in semi-enclosed coastal ecosystems and transitional waters habitatsimplications for the implementation of the European Water Framework Directive. Ecol. Indicat. doi:10.1016/ j.ecolind.2007.04.003.

Blocksom, K.A., 2003. A performance comparison of metric scoring methods for a multimetric index for mid-Atlantic highlands streams. Environ. Manage. 31 (5), 670-682.

Böhmer, J., Rawer-Jost, C., Zenker, A., Meier, C., Feld, C.K., Biss, R., Hering, D., 2004. Assessing streams in Germany with benthic invertebrates: development of a multimetric invertebrate based assessment system. Limnologica 34, 416-432.

Borja, A., 2006. The new European Marine Strategy Directive: difficulties, opportunities, and challenges. Mar. Pollut. Bull. 52, 239-242.

Borja, A., Dauer, D.M., Díaz, R., Llansó, R.J., Muxika, I., Rodríguez, J.G., Schaffner, L., in press. Assessing estuarine benthic quality conditions in Chesapeake Bay: a comparison of three indices. Ecol. Indicat., doi:10.1016/ j.ecolind.2007.05.003.

Borja, A., Franco, J., Pérez, V., 2000. A marine biotic index to establish the ecological quality of soft-bottom benthos within European estuarine and coastal environments. Mar. Pollut. Bull. 40 (12), 1100-1114.

Broeg, K., Lehtonen, K.K., 2006. Indices for the assessment of environmental pollution of the Baltic Sea coasts: integrated assessment of a multi-biomarker approach. Mar. Pollut. Bull. 53 (8-9), 508-522.
Brown, A.C., McLachland, A., 1990. Ecology of Sandy Shores. Elsevier, Amsterdam, 328 pp.

Caeiro, S., Costa, M.H., Ramos, T.B., Fernandes, F., Silveira, N., Coimbra, A., Medeiros, G., Painho, M., 2005. Assessing heavy metal contamination in Sado estuary sediment: An index analysis approach. Ecol. Indicat. 5, 151-169.

Carletta, J., 1996. Assessing agreement on classification tasks: the kappa statistic. Comput. Linguist. 22 (2), 249-254.

Carr, R.S., Gaston, G.R., 2002. Calcasieu Estuary Remedial Investigation/Feasibility Study (RI/FS): Baseline Ecological Risk Assessment (BERA). Document control no. 3282-941RTZ-RISKZ-14858.

Carvalho, S., Gaspar, M.B., Moura, A., Vale, C., Antunes, P., Gil, O., Fonseca, L.C., Falcão, M., 2006. The use of the marine biotic index AMBI in the assessment of the ecological status of the Óbidos lagoon (Portugal). Mar. Pollut. Bull. 52, 1414-1424.

Cicchetti, G., Latimer, J.S., Rego, S.A., Nelson, W.G., Bergen, B.J., Coiro, L.L., 2006. Relationships between near-bottom dissolved oxygen and sediment profile camera measures. J. Mar. Syst. 62, 124-141.

Costanza, R., 1996. Ecological economics: reintegrating the study of humans and nature. Ecol. Appl. 6 (4), 978-990.

Costanza, R., d'Arge, R., de Groot, R., Farber, S., Grasso, M., Hannon, B., Limburg, K., Naeem, S., O’Neill, R.V., Paruelo, J., Raskin, R.G., Sutton, P., van den Belt, M., 1997. The value of the world's ecosystem services and natural capital. Nature 387, 253-260.

Dauer, D.M., 1993. Biological criteria, environmental health and estuarine macrobenthic community structure. Mar. Pollut. Bull. 26, 249-257.

Dauvin, J.C., 2007. Paradox of estuarine quality: benthic indicators and indices, consensus or debate for the future. Mar. Pollut. Bull. 55, 271-281.

Dauvin, J.C., Ruellet, T., 2007. Polychaete/amphipod ratio revisited. Mar. Pollut. Bull. 55, 215-224.

Dauvin, J.C., Ruellet, T., Desroy, N., Janson, A.L., 2006. The ecological quality status of the Bay of Seine and the Seine estuary: use of biotic indices. Mar. Pollut. Bull. 55 (1-6), 241-257.

Deegan, L.A., Finn, J.T., Ayvazian, S.G., Ryder, C.A., Buonaccorsi, J., 1997. Development and validation of an estuarine biotic integrity index. Estuaries 20 (3), 601-617.

Díaz, R.J., Solan, M., Valente, R.M., 2004. A review of approaches for classifying benthic habitats and evaluating habitat quality. J. Environ. Manage. 73, 165-181.

Donath-Hernàndez, F.E., Loya-Salinas, D.H., 1989. Contribución al studio de la contaminación organica marina de la Bahia de Todos Santos, Baja California. Contribution to the study of organic marine pollution in Bahia de Todos Santos, Baja California. Cienc. Mar. 15 (1), 73-88.

Eagle, R.A., Rees, E.I., 1973. Indicator species-a case for caution. Mar. Pollut. Bull. 4, 25.

Eaton, L., 2001. Development and validation of biocriteria using benthic macroinvertebrates for North Carolina estuarine waters. Mar. Pollut. Bull. 42 (1), 23-30.

Engle, V.D., 2000. Application of the indicator evaluation guidelines to an index of benthic condition for Gulf of Mexico estuaries. In: Jackson, L.E., Kurtz, J.C., Fisher, W.S. (Eds.), Evaluation Guidelines for Ecological Indicators. EPA/ 620/R-99/005. U.S. Environmental Protection Agency, Office of Research and Development, Research Triangle Park, NC, p. 107 pp..

Engle, V.D., Summers, J.K., 1999. Refinement, validation, and application of a benthic condition index for Gulf of Mexico estuaries. Estuaries 22, 624-635.

Engle, V.D., Summers, J.K., Gaston, G.R., 1994. A benthic index of environmental condition of Gulf of Mexico estuaries. Estuaries 17, 372-384. 
Fausch, K.D., Lyons, J., Karr, J.R., Angermeier, P.L., 1990. Fish communities as indicators of environmental degradation. Am. Fish Soc. Symp. 8, 123-144.

Gaston, G.R., Rakocinski, C.F., Brown, S.S., Cleveland, L.M., 1998. Trophic function in estuaries: response of macrobenthos to natural and contaminant gradients. Mar. Freshwater Res. 49, 833-846.

Gibson, G.R., Bowman, M.L., Gerritsen, J., Snyder, B.D., 2000. Estuarine and Coastal Marine Waters: Bioassessment and Biocriteria Technical Guidance. EPA 822-B-00-024. U.S. Environmental Protection Agency, Office of Water, Washington, DC.

Glémarec, M., 1986. Ecological impact of an oil-spill: utilization of biological indicators. IAWPRC-NERC Conference, July 1985. IAWPRC J., vol. 18, pp. 203-211.

Gómez-Gesteira, J.L., Dauvin, J.C., 2000. Amphipods are good bioindicators of the impact of oil spills on soft-bottom macrobenthic communities. Mar. Pollut. Bull. 40 (11), 1017-1027.

Grall, J., Glémarec, M., 1997. Using biotic indices to estimate macrobenthic community perturbations in the Bay of Brest. Estuar. Coast. Shelf Sci. 44 (Suppl. A), 43-53.

Gray, J.S., 1979. Pollution induced changes in populations. Philos. Trans. R. Soc. Lond., Ser. B 286, 545-561.

Gray, J.S., Pearson, T.H., 1982. Objective selection of sensitive species indicative of pollution-induced change in benthic communities: a comparative methodology. Mar. Ecol. Prog. Ser. 9, 111-119.

Hale, S.S., Heltshe, J.F., in press. Signals from the benthos: development and evaluation of a benthic index for the nearshore Gulf of Maine. Ecol. Indicat., doi:10.1016/ j.ecolind.2007.04.004.

Hilsenhoff, W.L., 1987. An improved biotic index of organic stream pollution. Great Lakes Entomol. 20, 31-39.

Hily, C., 1984. Variabilité de la macrofauna benthique dans les milieux hypertrophiques de la Rade de Brest. Thése de Doctorat d'Etat, Univ. Bretagne Occidentale, vol. 1, 359 pp; vol. 2, $337 \mathrm{pp}$.

Hurlbert, S.H., 1971. The nonconcept of species diversity: a critique and alternative parameters. Ecology 52, 577-586.

Hyatt, E., 2001. Editorial. Ecol. Indicat. 1, 1-2.

Jameson, S.C., Erdmann, M.V., Karr, J.R., Gibson Jr., G.R., Potts, K.W., 2001. Charting a course toward diagnostic monitoring: a continuing review of coral reef attributes and a research strategy for creating coral reef indexes of biotic integrity. Bull. Mar. Sci. 69, 701-744.

Jeffrey, D.W., Wilson, J.G., Harris, C.R., Tomlinson, D.L., 1985. The application of two simple indices to Irish estuary pollution status. In: Wilson, J.G., Halcrow, W. (Eds.), Estuarine Management and Quality Assessment. Plenum Press, London.

Jenkins, S., Burrows, M., Garbary, D., Hawkins, S., Ingolffson, A., Moore, P., Sebens, K., Snelgrove, P., Wethey, D., Woodin, S., 2007. Comparisons of the Ecology of Shores Across the North Atlantic: Do Differences in Players Matter for Process? Special Feature. http://www.biology.duke.edu/corona/ Ecology/Jenkins.et.al.pdf.

Karr, J.R., 1991. Biological integrity: a long neglected aspect of water resource management. Ecol. Appl. 1, 66-84.

Karr, J., Chu, E.W., 1997. Biological monitoring: essential foundation for ecological risk assessment. Hum. Ecol. Risk Assess. 3, 993-1004.

Kennish, M.J., 1992. Ecology of Estuaries: Anthropogenic Effects. Marine Science Series. CRC Press, Boca Raton, FL.

Kennish, M.J., 1997. Pollution Impacts on Marine Biotic Communities. CRC Press.

Labrune, C., Amouroux, J.M., Sarda, R., Dutrieux, E., Thorin, S., Rosenberg, R., Grémare, A., 2006. Characterization of the ecological quality of the coastal Gulf of Lions (NW
Mediterranean). A comparative approach based on three biotic indices. Mar. Pollut. Bull. 52, 34-47.

Landis, J.R., Koch, G.G., 1977. The measurement of observer agreement for categorical data. Biometrics 33, 159-174.

Lerberg, S.B., Holland, F., Sanger, D.M., 2000. Responses of tidal creek macrobenthic communities to the effects of watershed development. Estuaries 23, 838-853.

Llansó, R.J., 2002. Methods for Calculating the Chesapeake Bay Benthic Index of Biotic Integrity. http://sci.odu.edu/ chesapeakebay/data/benthic/BIBIcalc.pdf.

Llansó, R.J., Scott, L.C., Dauer, D.M., Hyland, J.L., Russell, D.E., 2002a. An estuarine benthic index of biotic integrity for the Mid-Atlantic Region of the United States. I. Classification of assemblages and habitat definition. Estuaries 25 (6A), 1219-1230.

Llansó, R.J., Scott, L.C., Hyland, J.L., Dauer, D.M., Russell, D.E., Kurtz, F.W., 2002b. An estuarine benthic index of biotic integrity for the Mid-Atlantic Region of the United States. II. Index development. Estuaries 25 (6A), 1231-1242.

Mancinelli, G., Fazi, S., Rossi, L., 1998. Sediment structural properties mediating dominant feeding type's patterns in soft-bottom macrobenthos of the Northern Adriatic Sea. Hydrobiologia 367 (1-3), 211-222.

Marín-Guirao, L., Cesar, A., Marín, A., Lloret, J., Vita, R., 2005. Establishing the ecological quality status of soft-bottom mining-impacted coastal water bodies in the scope of the Water Framework Directive. Mar. Pollut. Bull. 50 (4), 374-387.

Marques, J.C., Maranhão, P., Pardal, M.A., 1993. Human impact assessment on the subtidal macrobenthic community structure in the Mondego estuary (Western Portugal). Estuar. Coast. Shelf Sci. 37, 403-419.

Marques, J.C., Nielsen, S.N., Pardal, M.A., Jørgensen, S.E., 2003. Impact of eutrophication and river management within a framework of ecosystems theories. Ecol. Model. 166, 147-168.

Maurer, D., Nguyen, H., Robertson, G., Gerlinger, T., 1999. The infaunal trophic index (ITI): its suitability for marine environment monitoring. Ecol. Appl. 9 (2), 699-713.

Muniz, P., Venturini, N., Pires-Vanin, A.M.S., Tommasi, L.R., Borja, A., 2005. Testing the applicability of a marine biotic index (AMBI) to assessing the ecological quality of softbottom benthic communities, South America Atlantic region. Mar. Pollut. Bull. 50, 624-637.

Muxika, I., Borja, Á., Bonne, W., 2005. The suitability of the marine biotic index (AMBI) to new impact sources along European coasts. Ecol. Indicat. 5, 19-31.

Muxika, I., Borja, A., Bald, J., 2007. Using historical data, expert judgement and multivariate analysis in assessing reference conditions and benthic ecological status, according to the European Water Framework Directive. Mar. Pollut. Bull. 55 (1-6), 16-29.

Nilsson, H.C., Rosenberg, R., 1997. Benthic habitat quality assessment of an oxygen stressed fjord by surface and sediment profile images. J. Mar. Syst. 11, 249-264.

Nilsson, H.C., Rosenberg, R., 2000. Succession in marine benthic habitat and fauna in response to oxygen deficiency: analysed by sediment profile-imaging and by grab samples. Mar. Ecol. Prog. Ser. 197, 139-149.

NRC (National Research Council), 2000. Ecological Indicators for the Nation. National Academy Press, Washington D.C., 180 pp.

O'Connor, B.D.S., Costolloe, J., Keegan, B.F., Rhoads, D.C., 1989. The use of REMOTS technology in monitoring coastal enrichment resulting from mariculture. Mar. Pollut. Bull. 20, 384-390.

Ott, W.R., 1978. Environmental Indices, Theory and Practise. Ann Arbour Science, Ann Arbour, MI.

Patrício, J., Ulanowick, R., Pardal, M.A., Marques, J.C., 2004. Ascendancy as an ecological indicator: a case study of 
estuarine pulse eutrophication. Estuar. Coast. Shelf Sci. 60, 23-35.

Paul, J.F., 2003. Developing and applying an index of environmental integrity for the US Mid-Atlantic region. J. Environ. Manage. 67, 175-185.

Paul, J.F., Scott, K.J., Campbell, D.E., Gentile, J.H., Strobel, C.S., Valente, R.M., Weisberg, S.B., Holland, A.F., Ranasinghe, J.A., 2001. Developing and applying a benthic index of estuarine condition for the Virginian biogeographic province. Ecol. Indicat. 1, 83-99.

Pearson, T.H., Rosenberg, R., 1978. Macrobenthic succession in relation to organic enrichment and pollution of the marine environment. Oceanogr. Mar. Biol., Annu. Rev. 16, 229-311.

Pereira, P., Vale, C., Ferreira, A.M., Pereira, E., Pardal, M.A., Marques, J.C., 2005. Seasonal variation of surface sediments composition in Mondego River estuary. J. Environ. Sci. Health A40, 1-13.

Pinn, E.H., Robertson, M.R., 2003. Macro-infaunal biodiversity and analysis of associated feeding guilds in the Greater Minch area, Scottish west coast. J. Mar. Biol. Assoc. 83, 433443.

Rakocinski, C.F., Brown, S.S., Gaston, G.R., Heard, R.W., Walker, W.W., Summers, J.K., 1997. Macrobenthic responses to natural and contaminant-related gradients in northern Gulf of Mexico estuaries. Ecol. Appl. 7, 1278-1298.

Reiss, H., Kröncke, I., 2005. Seasonal variability of benthic indices: an approach to test the applicability of different indices for ecosystem quality assessment. Mar. Pollut. Bull. 50, 1490-1499.

Rhoads, D.C., Germano, J.C., 1982. Characterization of organism-sediment relations using sediment profile imaging: an efficient method of remote ecological monitoring of the sea floor (REMOTS ${ }^{\mathrm{TM}}$ System). Mar. Ecol. Prog. Ser. 8, 115-128.

Rhoads, D.C., Germano, J.C., 1986. Interpreting long- term changes in benthic community structure: a new protocol. Hydrobiologia 142, 291-308.

Roberts, R.D., Gregory, M.R., Foster, B.A., 1998. Developing an efficient macrofauna monitoring index from an impact study—a dredge spoil example. Mar. Pollut. Bull. 36 (3), 231-235.

Rosenberg, R., Blomquist, M., Nilsson, H.C., Cederwall, H., Dimming, A., 2004. Marine quality assessment by use of benthic species-abundance distribution: a proposed new protocol within the European Union Water framework Directive. Mar. Pollut. Bull. 49, 728-739.

Rygg, B., 2002. Indicator species index for assessing benthic ecological quality in marine waters of Norway. Norwegian Institute for Water Research, Report no. 40114, pp. 1-32.

Salas, F., Neto, J.M., Borga, A., Marques, J.C., 2004. Evaluation of the applicability of a marine biotic index to characterize the status of estuarine ecosystems: the case of Mondego estuary (Portugal). Ecol. Indicat. 4, 215-225.

Salas, F., Marcos, C., Neto, J.M., Patrício, J., Pérez-Ruzafa, A., Marques, J.C., 2006. User-friendly guide for using benthic ecological indicators in coastal and marine quality assessment. Ocean Coast. Manage. 49, 308-331.

Schimmel, S.C., Benyi, S.J., Strobel, C.J., 1999. An assessment of the ecological condition of Long Island Sound, 1990-1993. Environ. Monit. Assess. 56, 27-49.

Schlacher, T.A., Wooldridge, T.H., 1996. How sieve mesh size affects sample estimates of estuarine benthic macrofauna. J. Exp. Mar. Biol. Ecol. 201, 159-171.

Schroeder, A., 2003. Community dynamics and development of soft bottom macrozoobenthos in the German Bight (North Sea) 1969-2000. PhD Dissertation. Bremen University.

Seegert, G., 2000. The development, use, and misuse of biocriteria with an emphasis on the index of biotic integrity. Environ. Sci. Policy 3, S51-S58.
Simboura, N., Zenetos, A., 2002. Benthic indicators to use in ecological quality classification of Mediterranean soft bottom marine ecosystems, including a new biotic index. Mediterr. Mar. Sci. 3, 77-111.

Simboura, N., Panayotidis, P., Papathanassiou, E., 2005. A synthesis of the biological quality elements for the implementation of the European Water Framework Directive in the Mediterranean ecoregion: the case of Saronikos Gulf. Ecol. Indicat. 5, 253-266.

Simboura, N., Papathanassiou, E., Sakellariou, D., 2007. The use of a biotic index (Bentix) in assessing long-term effects of dumping coarse metalliferous waste on soft bottom benthic communities. Ecol. Indicat. 7, 164-180.

Smith, R.W., Bergen, M., Weisberg, S.B., Cadien, D., Dalkey, A., Montagne, D., Stull, J.K., Velarde, R.G., 1998. Southern California Bight Pilot Project: Benthic Response Index for Assessing Infaunal Communities on the Mainland Shelf of Southern California. Southern California Coastal Water Research Project. http://www.sccwrp.org.

Smith, R.W., Bergen, M., Weisberg, S.B., Cadien, D., Dankey, A., Montagne, D., Stull, J.K., Velarde, R.G., 2001. Benthic response index for assessing infaunal communities on the Mainland Shelf of Southern California. Ecol. Appl. 11, 1073-1087.

Strickland, J.D.H., Parsons, T.R., 1972. A practical handbook of seawater analysis, Bulletin Fisheries Research Board of Canada, 2nd ed., vol. 167. 311 pp.

Teixeira, H., Salas, F., Borja, Á., Neto, J.M., Marques, J.C., in press. A benthic perspective in assessing the ecological status of estuaries: the case of the Mondego estuary (Portugal). Ecol. Indicat., doi:10.1016/j.ecolind.2007. 02.008.

USEPA, 2006. National Coastal Assessment, Northeast website. http://www.epa.gov/emap/nca/html/regions/ northeast.html.

USEPA, 2007. National Coastal Condition Report III. U.S. Environmental Protection Agency, Washington, DC.

Vale, C., Ferreira, A., Caetano, M., Brito, P., 2002. Elemental composition and contaminants in surface sediments of the Mondego river estuary, pp. 541-550. In: Pardal, M.A., Marques, J.C., Graça, M.A. (Eds.), Aquatic Ecology of the Mondego River Basin: Global Importance of Local Experience. Coimbra Imprensa da Universidade, 576 pp.

Valente, R.M., Rhoads, D.C., Germano, J.D., 1992. Mapping of benthic enrichment patterns in Narragansett Bay. Rhode Island Estuar. 15, 1-17.

Van Dolah, R.F., Hyland, J.L., Holland, A.F., Rosen, J.S., Snoots, T.R., 1999. A benthic index of biological integrity for assessing habitat quality in estuaries of the south-eastern USA. Mar. Environ. Res. 48, 269-283.

WCED (World Commission on Environment Development), 1987. Our Common Future. Oxford University Press, Oxford, 383 pp.

Weisberg, S.B., Ranasinghe, J.A., Dauer, D.M., Schaffner, L.C., Díaz, R.J., Frithsen, J.B., 1997. An estuarine benthic index of biotic integrity (B-IBI) for Chesapeake Bay. Estuaries 20, 149-158.

Wildish, D.J., Hargrave, B.T., MacLeod, C., Crawforl, C., 2003. Detection of organic enrichment near finfish net-pens by sediment profile imaging at SCUBA-accessible depths. J. Exp. Mar. Biol. Ecol. 285/286, 403-413.

Wilson, J.G., 2003. Evaluation of estuarine quality status at system level using the biological quality index and the pollution load index. Biol. Environ.: Proc. R. Irish Acad. 103B (2), 49-57.

Word, J.Q., 1978. The infaunal trophic index. Coastal Water Research Project Annual Report, Southern California Coastal Water Research Project, El Segundo, CA, pp. 19-39.

Word, J.Q., 1980. Classification of benthic invertebrates into infaunal trophic index feeding groups. Biennial Report, 1979-80, Coastal Water Research Project, Los Angeles, pp. 103-121. 
Word J.Q., 1990. The infaunal trophic index, a functional approach to benthic community analyses. PhD Dissertation. University of Washington, Seattle, Washington, USA.

Zenetos, A., Chadjianestis, I., Lantzouni, M., Simboura, M., Sklivagou, E., Arvanitakis, G., 2004. The Eurobulker oil spill: midterm changes of some ecosystem indicators. Mar. Pollut. Bull. 48 (1/2), 121-131.

Zettler, M.L., Schiedek, D., Bobertz, B., 2007. Benthic biodiversity indices versus salinity gradient in the southern Baltic Sea. Mar. Pollut. Bull. 55, 258-270.

Please cite this article in press as: Pinto, R. et al., Review and evaluation of estuarine biotic indices to assess benthic condition, Ecol. Indicat. (2008), doi:10.1016/j.ecolind.2008.01.005 